\title{
CIENCIAS DE LA MENTE Y RESPONSABILIDAD JURÍDICA: DOS RETOS*
}

\section{SCIENCES OF THE MIND AND LEGAL RESPONSIBILITY: TWO CHALLENGES}

\author{
Fernando Efraín Rudy HiLlER*
}

\section{Resumen:}

Este artículo evalúa el impacto de las ciencias de la mente y el comportamiento sobre el concepto y la práctica de la responsabilidad jurídica, particularmente sobre el derecho penal. Existen dos posiciones polares al respecto: por un lado, hay quienes sostienen que las ciencias de la mente muestran que la responsabilidad (jurídica y moral) es una quimera y por tanto que los sistemas jurídicos existentes deben ser radicalmente revisados. Por el otro, hay quienes piensan que, dado que las prácticas de atribución de responsabilidad son prácticas normativas, éstas son fundamentalmente inmunes a los descubrimientos científicos acerca del comportamiento humano. Contra ambas posiciones, argumento que dichos descubrimientos, si bien no muestran que la psicología de sentido común en la que se basa el derecho penal está fundamentalmente equivocada, tampoco son irrelevantes para evaluar su corrección. Defiendo esta tesis apelando a los descubrimientos de la psicología social situacionista, los cuales, sostengo, desmienten uno de los supuestos centrales de aquélla, a saber, el supuesto de que las capacidades racionales constitutivas de la agencia responsable son estables a través de distintos contextos. Finalmente, ilustro la relevancia de esta conclusión para el derecho examinando las "leyes del buen samaritano", las cuales imponen sanciones penales a quienes no ayudan a otros en situaciones de emergencia.

* Artículo recibido el 5 de septiembre de 2019 y aceptado para su publicación el 18 de febrero de 2020.

** Investigador en el Instituto de Investigaciones Filosóficas de la UNAM, correo electrónico: ferudy@alumni.stanford.edu, ORCID: https://orcid.org/0000-00027977-1216. 
FERNANDO EFRAÍN RUDY HILLER

\title{
Palabras clave:
}

Responsabilidad jurídica, psicología de sentido común, psicología social, capacidades racionales, leyes del buen samaritano.

\begin{abstract}
:
This paper examines the impact of the sciences of mind and behavior on the concept and practice of legal responsibility, particularly on criminal law. There are two opposite positions on this issue: on the one hand, there are those who think that empirical sciences already show that (moral and legal) responsibility is illusory and thus conclude that existing legal systems must be radically revised. On the other, there are those who think that since responsibility practices are essentially regulatory ones, they are basically resistant to scientific discoveries about human conduct. Against both positions, I argue that although these discoveries may not show that the common-sense psychology on which criminal law rests is fundamentally misguided, they are not irrelevant for assessing it either. To illustrate my position I draw upon findings from situationist social psychology and in particular on the "Bystander Effect," according to which the mere presence of several persons during an emergency lowers their propensity to help, regardless of their particular personality traits and moral attitudes. Finally, I explain the importance this discovery has for legal purposes, focusing on so-called Good Samaritan Laws that impose penal sanctions on those who fail to help others in emergency.
\end{abstract}

\section{Keywords:}

Legal Responsibility, Folk Psychology, Social Psychology, Rational Capacities, Good Samaritan Laws. 
CIENCIAS DE LA MENTE Y RESPONSABILIDAD JURÍDICA...

SUMARIO: I. Introducción II. La psicología de sentido común y el derecho. III. El reto global. IV. El reto local. $V$. El situacionismo y las leyes del buen samaritano. VI. Conclusión. VII. Referencias.

\section{INTRODUCCIÓN}

No hay disputa más acalorada en la naciente disciplina del "neuroderecho" que el del potencialmente devastador golpe que las ciencias de la mente ${ }^{1}$ pudieran asestarle al concepto y a la práctica de la responsabilidad jurídica. En un extremo de esta disputa se encuentran quienes, con base en los avances en el estudio científico de la mente y el cerebro, concluyen que las concepciones tradicionales de la responsabilidad jurídica y moral son una quimera y, en consecuencia, que los sistemas jurídicos existentes, y en particular el derecho penal, tarde que temprano tendrán que ser radicalmente revisados. ${ }^{2}$ En el otro extremo se hallan quienes sostienen que la evidencia actualmente disponible no pone en absoluto en peligro la integridad del derecho y, más aún, que hay buenas razones para dudar que cualquier evidencia futura pueda hacerlo. ${ }^{3}$ Una dificultad

1 Incluyo dentro de este rubro a las neurociencias, las ciencias cognitivas, la psicología cognitiva y la psicología social. A esta última la etiqueta "ciencia del comportamiento" le resulta más adecuada pero, por economía de lenguaje, en este trabajo me referiré sumariamente a todas estas disciplinas como "ciencias de las mente".

2 Greene, Joshua y Cohen, Jonathan, "For the Law, Neuroscience Changes Nothing and Everything", Philosophical Transactions of the Royal Society of London, vol. 359, núm. 1451, 2004, pp. 1775-85; Sapolsky, Robert, "The Frontal Cortex and the Criminal Justice System", Philosophical Transactions of the Royal Society of London, vol. 359, 2004, núm. 1451, pp. 1787-96; Dawkins, Richard, "Let's All Stop Beating Basil's Car", Edge: The World Question Center, 2006, disponible en: https:// www.edge.org/q2006/q06_9.html; Cashmore, Anthony, "The Lucretian Swerve: The Biological Basis of Human Behavior and the Criminal Justice System", Proceedings of the National Academy of Sciences, 2010, vol. 107, núm. 10, pp. 4499-4504; Davies, Paul, "Skepticism Concerning Human Agency: Sciences of the Self Versus 'Voluntariness' in the Law", en Vincent, Nicole (ed.), Neuroscience and Legal Responsibility, Oxford, Oxford University Press, 2013, pp. 113-130.

3 Glannon, Walter, "Neurobiology, Neuroimaging, and Free Will", Midwest Studies in Philosophy, vol. 29, 2005, pp. 68-82; Gazzaniga, Michael, "The Law and Neu- 
importante con esta manera de conducir el debate acerca del potencial impacto de las ciencias de la mente sobre la responsabilidad jurídica - el enfoque del todo o nada- es que oscurece una tercera posibilidad, a saber, que la evidencia científica pudiera mostrar que la psicología de sentido común en la que se basa el derecho es, si no globalmente inadecuada, sí localmente defectuosa. En otras palabras, bien pudiera ser el caso que dicha evidencia, si bien no muestra que la persona racional presupuesta en el derecho no existe, sí sugiere que, en ciertos aspectos claramente identificables, sus capacidades racionales son más limitadas de lo que ordinariamente suponemos. Más importante aún, bien pudiera ocurrir que ciertas disposiciones jurídicas no sólo no reconocen estos límites sino que, al contrario, prescriben ciertos comportamientos que los pasan por alto. Si ello es así, entonces, en lugar de una amenaza inminente para la integridad del derecho, las ciencias de la mente serían potenciales aliadas de éste en la creación de disposiciones jurídicas más realistas y justas.

En consonancia con lo anterior, el presente artículo tiene dos objetivos principales. Primero, exponer y criticar lo que llamaré "el reto global" a la responsabilidad jurídica proveniente de las ciencias de la mente. Aquí me abocaré a criticar los dos principales argumentos que suelen esgrimirse a favor de la conclusión de que la evidencia empírica refuta a la psicología de sentido común presupuesta en el derecho y, en consecuencia, que las prácticas jurídicas relacionadas con las atribuciones de responsabilidad penal son fundamentales defectuosas (al menos bajo una concepción retributiva de dichas prácticas). Mi segundo objetivo es mostrar que, a pesar de que el reto global falla, un reto más modesto - el "reto local" - a la psicología de sentido común es más plausible a la luz de la evidencia actualmente disponible. Específicamente, argumentaré, con base en evidencia proveniente de la psicología social, que uno de los supues-

roscience", Neuron, vol. 60, pp. 412-5, 2008; Morse, Stephen, "Determinism and the Death of Folk Psychology: Two Challenges to Responsibility from Neuroscience", Minnesota Journal of Law, Science and Technology, 2008, vol. 9, núm. 1, pp. 1-36; Morse, Stephen, "Responsibility and Mental Capacity", en Vincent, Nicole (ed.), Neuroscience and Legal Responsibility, Oxford, Oxford University Press, 2013, pp. 27-47. 
tos centrales de la psicología de sentido común empleada en el derecho - el supuesto de que las capacidades racionales relevantes para las atribuciones de responsabilidad son estables a través de diferentes circunstancias - es falso. Sostendré, por el contrario, que dicha evidencia demuestra que las capacidades cognitivas y volitivas requeridas para detectar y responder adecuadamente a consideraciones normativas son extraordinariamente sensibles a influencias situacionales en apariencia nimias, algunas de las cuales pueden interferir significativamente con el ejercicio de dichas capacidades y, por tanto, poner en duda la corrección de ciertas atribuciones ordinarias de responsabilidad.

Ilustraré esta tesis apelando al cúmulo de evidencia "situacionista" en psicología social que muestra que factores situacionales aparentemente irrelevantes pueden afectar significativamente la propensión de las personas a prestar ayuda con independencia de cuáles sean sus convicciones morales. Sostendré además que la influencia de dichos factores sobre las capacidades racionales no sólo no es reconocida por el derecho sino que, por el contrario, existen disposiciones jurídicas que presuponen que dicha influencia no existe o no es relevante. Un ejemplo claro son las llamadas "leyes del buen samaritano" que imponen sanciones penales a quienes no auxilian a otros en situaciones de emergencia, siempre y cuando el costo de ayudar sea bajo y no exista ningún impedimento obvio para hacerlo. La conclusión que buscaré establecer es que, a pesar de que nuestras intuiciones ordinarias nos dicen que es razonable esperar de personas racional y moralmente normales que presten ayuda en dichas circunstancias y por tanto que son responsables por sus omisiones cuando no lo hacen, estas intuiciones no son confiables a la luz de la evidencia aducida. Se sigue de ello que las disposiciones jurídicas que descansan en dichas intuiciones deben ser revisadas.

La estructura del trabajo es la siguiente. En la sección 2 bosquejo los tres rasgos centrales de la psicología de sentido común -y de la persona racional- presupuesta en el derecho y, más específicamente, en el derecho penal. ${ }^{4}$ En la sección 3 expongo y critico el reto

4 En este trabajo me refiero genéricamente al derecho y al derecho penal sin ocuparme de las importantes diferencias que existen entre el derecho continental y 
global según el cual la psicología de sentido común está fundamentalmente equivocada y, por lo tanto, no puede servir de base al derecho penal. En la sección 4 presento el reto local y en la sección 5 ilustro su relevancia para el derecho tomando como ejemplo las leyes del buen samaritano. Finalmente, en la sección 6 concluyo con un breve resumen de las principales conclusiones alcanzadas en el trabajo.

\section{LA PSICOLOGÍA DE SENTIDO COMÚN Y EL DERECHO}

\section{Los supuestos básicos de la psicología de sentido común}

Por "psicología de sentido común" me refiero al conjunto de suposiciones ordinarias acerca de los estados mentales de las personas que nos permiten explicar, predecir y evaluar su comportamiento en un amplio rango de circunstancias. Si, por ejemplo, durante una fiesta vemos a una persona acercarse a la mesa de bocadillos y tomar una servilleta, podemos explicar su comportamiento apelando a sus deseos (desea comer un bocadillo) y creencias (cree que los bocadillos están en la mesa y cree además que tomar el bocadillo con una servilleta es lo que la etiqueta exige). Este mismo modelo nos permite predecir las acciones de otros: retomando el ejemplo, el anfitrión de la fiesta sabe de antemano que si coloca los bocadillos y las servilletas en un lugar visible, los invitados se acercarán a ellos y los tomarán de cierta manera. Finalmente, este modelo nos permite evaluar el comportamiento de las personas como más o menos racional. Por ejemplo, juzgaremos como irracional a un hombre que, deseando comprar una bebida de la máquina expendedora, deposita una moneda en su sacapuntas con base en su creencia de que ello es el medio adecuado para obtenerla. ${ }^{5}$

el anglosajón, debido a que ambos comparten los supuestos básicos de la psicología de sentido común que discuto a continuación.

5 El ejemplo aparece en Nagel, Thomas, The Possibility of Altruism, Princeton, NJ, Princeton University Press, 1970, p. 34. 
CIENCIAS DE LA MENTE Y RESPONSABILIDAD JURÍDICA...

Lo que comparten estas tres operaciones que la psicología de sentido común nos permite realizar —explicar, predecir y evaluar el comportamiento humano- es la concepción de las personas como seres racionales, es decir, agentes que actúan a la luz de sus creencias (mayormente verdaderas) para obtener aquello que desean (concebido como algo bueno). Como señala Stephen Morse, el derecho, y sobre todo el derecho penal, dependen de manera fundamental tanto de la psicología de sentido común como de la concepción de las personas como seres racionales en el sentido recién descrito. ${ }^{6}$

La psicología de sentido común descansa en tres supuestos básicos que resultan esenciales para el derecho. En primer lugar está el supuesto de causación mental, a saber, la presunción de que ciertos estados mentales de las personas (por ejemplo, sus deseos e intenciones) son causalmente relevantes en la producción de sus acciones, de lo que se sigue que la explicación de su comportamiento debe apelar fundamentalmente a dichos estados mentales.

En segundo lugar está el supuesto de sensibilidad a razones, es decir, la idea de que las personas actúan — no siempre, pero con suficiente frecuencia- con base en razones. Este supuesto juega un doble papel. Por un lado, hace posible ofrecer explicaciones racionalizadoras del comportamiento, esto es, explicaciones que permiten entender por qué determinada acción tenía sentido para el agente a la luz de sus deseos y creencias. ${ }^{7}$ Por otro lado, sustenta la idea de que las acciones son racionalmente evaluables. Volviendo al ejemplo de Nagel, es apropiado juzgar como irracional a la persona que deposita una moneda en su sacapuntas para obtener un refresco porque esta acción resulta defectuosa a la luz de las razones que ella misma posee (en este caso, relacionadas con aliviar su sed). Además, dado que tanto la moral como el derecho regulan el comportamiento

6 "El derecho penal es una empresa completamente basada en la psicología ordinaria" (Morse, Stephen, "Responsibility and Mental Capacity", cit., p. 27). "Lo que el derecho requiere es la concepción de sentido común de la racionalidad" (ibidem, p. 32). (Todas las traducciones del inglés son mías.) Ahondo en este punto en la subsección 2.2.

7 Véase Davidson, Donald, “Actions, Reasons, and Causes”, en Davidson, Donald, Essays on Actions and Events, Oxford, Oxford University Press, 1980, pp. 3-20. 


\section{FERNANDO EFRAÍN RUDY HILLER}

ofreciendo razones perentorias para la acción, ${ }^{8}$ el supuesto de sensibilidad a razones permite evaluar a los agentes a la luz de éstas.

En tercer lugar está el supuesto de capacidades racionales generales, según el cual las capacidades racionales que poseen las personas para percatarse de, y actuar con base en, las razones pertinentes de cada caso son capacidades generales, esto es, estables a través de diferentes circunstancias. ${ }^{9}$ Ello implica, por ejemplo, que si alguien es capaz de percatarse en la situación $X$ de que alguien necesita ayuda y es capaz además de actuar en consecuencia, entonces es razonable esperar que, ceteris paribus, dicha persona será igualmente capaz de ambas cosas en la situación Y. Ello no implica, desde luego, que sea razonable esperar que la persona en cuestión responderá adecuadamente en cualquier circunstancia posible; por ejemplo, no es razonable esperar que ayudará a otro cuando ello conllevaría poner en riesgo su propia vida o invertir la mayoría de sus recursos. Sin embargo, el supuesto de capacidades racionales generales sí implica que la clase de situaciones que interfieren con el ejercicio de éstas -en el sentido relevante para las atribuciones de responsabilidad- es limitada y, además, que es coextensiva con las exenciones y excusas reconocidas por la moral ordinaria y el derecho. ${ }^{10}$

8 Véanse, respectivamente, Smith, Michael, The Moral Problem, Malden, MA, Blackwell, 1994; y Raz, Joseph, 1975, Practical Reason and Norms, Londres, Hutchinson.

9 La locución "capacidad general" en ocasiones se emplea en un sentido distinto. En este otro sentido, un agente tiene la capacidad general de realizar algo si posee las habilidades necesarias para llevarlo a cabo pero carece de la oportunidad para hacerlo (véase Mele, Alfred, "Agents' Abilities", Noûs, vol. 37, núm. 3, pp. 447$470,2002)$. Por ejemplo, podemos decir que un pianista tiene la capacidad general de tocar la sonata núm. 5 de Beethoven pero no la capacidad específica para ello si, en un momento dado, no tiene un piano a su alcance. En este trabajo la locución "capacidad general" se usa únicamente en el sentido indicado en el cuerpo del texto.

10 En la literatura sobre responsabilidad moral es usual trazar la distinción entre aquellos factores que exentan y aquellos que excusan de responsabilidad (véase Wallace, Jay, Responsibility and the Moral Sentiments, Cambridge, Harvard University Press, 1994, caps. 5 y 6). Las exenciones muestran que el agente en cuestión no es (en general o en una situación específica) un agente responsable, es decir, que carece de las capacidades mínimas para ser considerado como tal; mientas que las excusas muestran que un acto incorrecto producido por un agente que sí posee dichas 
CIENCIAS DE LA MENTE Y RESPONSABILIDAD JURÍDICA...

Es importante notar que estos tres supuestos básicos de la psicología de sentido común son independientes entre sí. Por ejemplo, podríamos aceptar el supuesto de causación mental y rechazar el supuesto de sensibilidad a razones ${ }^{11} \mathrm{o}$, a la inversa, aceptar el supuesto de sensibilidad a razones y rechazar el de causación mental. ${ }^{12}$ Por otro lado, aceptar el supuesto de capacidades racionales generales y rechazar el de sensibilidad a razones es menos plausible ya que, al menos en el presente contexto, parte de lo que implica ser racional es precisamente ser sensible a razones. ${ }^{13}$ Sin embargo, como veremos más adelante, la posibilidad inversa - aceptar el supuesto de sensibilidad a razones y rechazar el de capacidades racionales generales - es sumamente plausible. Ello conduce a una concepción de las personas en la que éstas son sensibles a razones pero no en cualquier circunstancia y no respecto de cualquier clase de razones; en otras palabras, en dicha concepción las capacidades para detectar y responder adecuadamente a las razones pertinentes del caso no son estables a través de distintas circunstancias sino que están indexadas a contextos específicos de acción. ${ }^{14}$ Como explicaré en detalle abajo (subsección 4.3.1), una concepción precisamente de esta naturaleza resulta plausible a la luz de la evidencia aducida por

capacidades no es imputable a éste. Las exenciones más usuales son la demencia y la minoría de edad, mientras que las excusas usuales son la coerción y la ignorancia. Si bien en el derecho penal no se traza tal distinción explícitamente, por razones que quedarán claras más adelante (véase la sección 5.2) en este trabajo sí lo haré.

11 Imagínese por ejemplo una concepción de las personas como seres que actúan siguiendo siempre el deseo más fuerte, independientemente de las razones en contra de su satisfacción.

12 Ello implicaría pensar que los estados mentales conscientes, incluyendo las deliberaciones racionales, son meros epifenómenos, es decir, que no están causalmente relacionados con las acciones. Como veremos en la sección 3, el psicólogo social Daniel Wegner sostiene una posición de este tipo.

13 Digo "al menos en el presente contexto" porque en áreas distintas a la filosofía del derecho existe una genuina discusión acerca de si la racionalidad consiste en responder a razones o si consiste en algo distinto como, por ejemplo, la coherencia entre estados mentales. Véase Broome, John, Rationality through Reasoning, Malden, Wiley-Blackwell, 2013, cap. 5.

14 Véase Vargas, Manuel, Building Better Beings: A Theory of Moral Responsibility, Oxford, Oxford University Press, 2013, p. 205. 
el reto local a la responsabilidad jurídica. Por el momento, basta con haber notado la modularidad de los supuestos básicos de la psicología de sentido común, lo cual abre la puerta a una reforma parcial - en oposición a un rechazo tajante - tanto de ésta como de la imagen de la persona racional asociada con ella.

\section{La persona racional y el derecho}

Señalé antes que el derecho, y en especial el derecho penal, presuponen a la psicología de sentido común y a la imagen de la persona racional asociada con ella. A continuación sustentaré esta afirmación apelando de nuevo a los tres supuestos básicos descritos arriba.

En primer lugar, el supuesto de causación mental - el supuesto de que las personas son capaces de controlar sus acciones a través de ciertos estados mentales- es esencial para comprender la función central del derecho como guía de la acción. ${ }^{15}$ La función primaria de los sistemas jurídicos es regular la conducta de los seres humanos por medio de directrices dirigidas precisamente a aquellos agentes cuya conducta se busca influir. Para que este método de regulación tenga sentido, es necesario suponer que las personas son capaces de adecuar su conducta a los requerimientos jurídicos aplicables a través de sus acciones y omisiones intencionales; en otras palabras, es necesario suponer que sus estados mentales conscientes -sus creencias acerca de los requerimientos jurídicos aplicables y sus intenciones de adecuar su conducta a éstos- son, por lo general, causalmente efectivos en la producción de sus acciones y omisiones. De lo contrario, el derecho sería incapaz de guiar la conducta humana.

El supuesto de causación mental es esencial también para el derecho penal en particular, pues dos de los elementos básicos empleados en éste para tipificar ciertas conductas como delictuosas - el elemento de acción y el elemento de mens rea o culpabilidad- presuponen que los estados mentales conscientes de las personas juegan un rol central en la producción de su comportamiento. Por lo

15 Para esta concepción del derecho, véase Shapiro, Scott, "Law, Morality, and the Guidance of Conduct”, Legal Theory, vol. 6, 2000, pp. 127-170. 
que toca al elemento de acción, en el derecho penal una acción se define como un movimiento corporal voluntario y, a su vez, la noción de voluntariedad se define apelando al papel que desempeña la conciencia en la producción de los movimientos de la persona. ${ }^{16}$ Aunque no suele especificarse exactamente qué papel juega la conciencia, ${ }^{17}$ sí se presume que podemos distinguir intuitivamente entre aquellos movimientos corporales producidos y guiados por la conciencia de la persona y aquellos que no. Ejemplos de estos últimos son actos reflejos, movimientos producidos durante un episodio de sonambulismo o hipnosis o aquellos movimientos causados por una fuerza exterior irresistible. El punto importante es que una piedra angular del derecho penal es la idea de que la conciencia de la persona es decir, sus estados mentales conscientes como deseos e intenciones- es causalmente efectiva en la producción de un rango significativo de sus movimientos corporales.

Por otro lado, el elemento de mens rea o culpabilidad involucra directamente los estados mentales de la persona, pues desde el punto de vista jurídico resulta esencial saber qué estados mentales albergaba el sujeto al momento de producir un daño para poder determinar de qué tipo de conducta criminal es responsable. Un mismo movimiento voluntario - por ejemplo, mover el dedo índice para jalar el gatillo de un arma- será calificado de modo muy diferente dependiendo de si el sujeto sabía que el arma estaba cargada y de si tenía además la intención de asesinar a la persona a quien apuntaba (homicidio doloso) o si, por el contrario, el sujeto ignoraba que lo estaba y carecía además de la intención de producir daño (homicidio culposo). Nuevamente, el punto importante es que la coherencia de este aspecto del derecho penal - la distinción entre tipos penales con base en los estados mentales del sujeto- depende del supuesto de que estos últimos son causalmente eficaces en la producción de la acción que condujo al daño.

16 Véase, por ejemplo, la definición de acto voluntario en la sección 2.01 del Model Penal Code estadounidense.

17 Una excepción es Moore, Michael, Act and Crime: The Philosophy of Action and its Implications for Criminal Law, Oxford, Oxford University Press, 1993, en el que se investiga a detalle la relevancia de la teoría causal de la acción para el derecho penal. 
En segundo lugar, el supuesto de sensibilidad a razones está también incorporado al derecho de manera fundamental. El derecho se dirige a los agentes en tanto seres racionales, capaces de detectar y verse motivados por las razones pertinentes. ${ }^{18} \mathrm{En}$ el caso particular del derecho penal, uno de los propósitos básicos que se persigue al tipificar cierta conducta como delictuosa es hacer patente que existen razones decisivas para evitarla. Esas razones no son puramente prudenciales (como evadir el castigo) sino también morales (en ocasiones la conducta prohibida es mala en sí misma, es decir, independientemente de su prohibición jurídica, por lo que existen razones morales decisivas para no realizarla), y se asume que los agentes son capaces de tomar en cuenta ambas al deliberar acerca de cómo actuar. Además, la práctica del juicio penal también se basa en el supuesto de sensibilidad a razones, puesto que el acusado es llamado a responder por su conducta y ello incluye la posibilidad de ofrecer razones por las cuales no debe ser condenado. ${ }^{19}$ Finalmente, y bajo una concepción reformista del castigo, el castigo penal presupone la capacidad del criminal de responder adecuadamente a razones en tanto aquél aspira a que éste reconozca que ha obrado mal, se arrepienta de lo que ha hecho y realice las reparaciones morales necesarias. $^{20}$

En tercer lugar, el supuesto de capacidades racionales generales está también sólidamente arraigado en el derecho, particularmente en el derecho penal, pues una condición necesaria de la imputabilidad jurídica es la posesión de las capacidades cognitivas y volitivas requeridas para entender lo que la ley exige y actuar en consecuencia. ${ }^{21}$ Esta concepción de la imputabilidad suele ir asociada con el supuesto de que las capacidades pertinentes son estables a través

18 Raz, Joseph, op. cit., cap. 5.

19 Duff, Anthony, Farmer, Lindsay, Marshall, Sandra y Tadros, Victor, The Trial on Trial: Towards a Normative Theory of the Criminal Trial, vol. 3, Oxford, Hart, 2007, cap. 5.

20 Duff, Anthony, Punishment, Communication and Community, Nueva York, Oxford University Press, 2001.

21 Hart, Herbert, 1968, "Postscript: Responsibility and Retribution", en Hart, Herbert, Punishment and Responsibility, Oxford, Clarendon Press, 1968, pp. 210237. 
CIENCIAS DE LA MENTE Y RESPONSABILIDAD JURÍDICA...

de un amplio rango de circunstancias. Si bien esta suposición rara vez es articulada, mucho menos defendida, explícitamente, ${ }^{22}$ su presencia es clara en los escritos de quienes adoptan la concepción "capacitaria” de la imputabilidad. Por ejemplo, Morse afirma que:

Los agentes responsables son dejados en libertad [para actuar como mejor les parezca] bajo la teoría de que un agente racional siempre podría reconocer la incorrección y peligro para sí mismo de violar criminalmente los legítimos intereses de otros. ${ }^{23}$

La idea de que, al menos en principio, un agente racional siempre está en posición de reconocer la incorrección jurídica de su conducta - particularmente cuando se trata de actos potencialmente criminales - sólo tiene sentido bajo el supuesto de que las capacidades racionales requeridas para ello son estables a través de un amplio rango de circunstancias. Como señalé arriba, las únicas limitantes a este supuesto que son aceptadas como relevantes para las atribuciones de responsabilidad son las excusas y exenciones jurídicamente reconocidas. En ausencia de éstas, la práctica jurídica se apega a la idea de que una persona racional siempre está en posición de adecuar su conducta a las exigencias relevantes. ${ }^{24}$

Antes de proseguir, debo aclarar que el ámbito de aplicación de mi análisis concierne exclusivamente a las capacidades racionales que son necesarias y suficientes para que una persona sea objeto de lo que Hart llama "liability-responsibility", esto es, para que sea sus-

22 Una excepción es Morse, quien explícitamente sostiene que "Los agentes jurídicamente responsables son personas que poseen la capacidad general para comprender y guiar su comportamiento por buenas razones en diferentes contextos jurídicos" (Morse, Stephen, "Determinism and the Death of Folk Psychology..., cit., p. 7, cursivas añadidas).

23 Morse, Stephen, "Responsibility and Mental Capacity", cit., p. 30, énfasis añadido.

24 Por ejemplo, Anthony Duff afirma que "En ausencia de tal desorden o incapacidad [ej., la psicopatía], podemos tratar a la persona como en principio persuadible [para actuar correctamente], que es lo que importa para la responsabilidad" (Duff, Anthony, "What Kind of Responsibility Must Criminal Law Presuppose?”, en Swinburne, Richard (ed.) Free Will and Modern Science, Oxford, Oxford University Press, 2011, p. 190, cursivas añadidas). 
ceptible de castigo jurídico por sus acciones. ${ }^{25}$ Este tipo de responsabilidad, según Hart, se basa en lo que él llama "capacity-responsibility", esto es, en la posesión de ciertas capacidades cognitivas y volitivas que hacen a la persona capaz de entender lo que la ley exige y actuar en consecuencia. ${ }^{26} \mathrm{Mi}$ propuesta no atañe al razonamiento moral o jurídico en general, ni mucho menos a la normatividad jurídica en su conjunto, sino únicamente a las capacidades racionales antes referidas. Además, es importante señalar que ninguno de mis argumentos guarda relación alguna con la cuestión acerca de cómo impacta el situacionismo a la agencia epistémica. ${ }^{27}$ Esta omisión es admisible dado que ambos tipos de agencia — la agencia responsable y la agencia epistémica- no sólo son distintos entre sí sino que, además, ninguno de los principales teóricos de la agencia responsable a nivel individual (tanto moral como jurídica) piensan que el análisis de ésta conlleve o presuponga un análisis de la agencia epistémica. Es cierto que un elemento esencial de la agencia responsable es la llamada "condición epistémica", ${ }^{28}$ pero dicha condición no tiene nada que ver con la agencia epistémica sino que concierne más bien a los estados de conciencia que son relevantes para las atribuciones de responsabilidad. Si, como explico más adelante, la evidencia situacionista muestra que factores situacionales aparentemente irrelevantes pueden afectar de manera significativa el ejercicio de las capacidades constitutivas de la agencia responsable a nivel individual, ello basta para establecer su relevancia para el derecho aun dejando completamente de lado la relación entre el situacionismo y la epistemología. ${ }^{29}$

25 Agradezco a un dictaminador anónimo por haberme instado a clarificar el ámbito de aplicación de mi análisis.

26 Hart, Herbert, op. cit.

27 Véase el texto Olin, Lauren y Doris, John, "Vicious minds: Virtue Epistemology, Cognition, and Skepticism”, Philosophical Studies, vol. 168, núm. 3, pp. 665-692, 2014, para un análisis de la relevancia de la evidencia situacionista para la agencia epistémica y la epistemología en general.

28 Véase mi artículo al respecto Rudy-Hiller, Fernando, "The Epistemic Condition for Moral Responsibility", en Zalta, Edward N. (ed.), The Stanford Encyclopedia of Philosophy (edición verano 2018), disponible en: https://plato.stanford.edu/archives/fall2018/entries/moral-responsibility-epistemic/.

29 Véase el texto de Montemayor, Carlos y Cáceres, Enrique, "Agency and Legal 
CIENCIAS DE LA MENTE Y RESPONSABILIDAD JURÍDICA...

\section{EL RETO GLOBAL}

Hemos visto que el derecho en general, y el derecho penal en particular, presuponen la psicología de sentido común descrita arriba y la imagen de la persona racional asociada con ella. Ahora bien, si existiera evidencia científica que pusiera en duda la adecuación empírica de ambas a nivel global ello a su vez pondría en duda la adecuación normativa del derecho, pues éste no estaría en posición de imponer obligaciones y asignar penas si las personas no fueran el tipo de agentes que pueden cumplir con aquéllas (al menos de la forma en que ordinariamente se asume que lo hacen). Los proponentes del reto global contra la responsabilidad jurídica argumentan que ya existe evidencia empírica suficiente para concluir que el supuesto de causación mental es falso y, por tanto, que también lo es el supuesto de que el comportamiento humano es producto de deliberaciones racionales. ${ }^{30}$ Si éste fuera el caso, entonces la concepción del derecho como guía de la acción sería insostenible, así como también lo sería el derecho penal basado como está en las ideas de voluntariedad y mens rea. En esta sección describiré y criticaré los dos argumentos principales que constituyen el reto global: el argumento reduccionista (3.1) y el argumento modular (3.2).

\section{El argumento reduccionista}

La afirmación principal de los proponentes del reto global es la siguiente:

Responsibility: Epistemic and Moral Considerations", Problema. Anuario de Filosofía y Teoría del Derecho, núm. 13, 2019, pp. 99-127, para una discusión acerca de la interrelación entre agencia moral y epistémica y su relevancia para la normatividad jurídica en general

30 Ello no implica que el supuesto de sensibilidad a razones sea falso tout court, pues aún pudiera ser el caso que las personas son capaces de detectar las razones relevantes en distintas situaciones aun cuando su comportamiento no sea producto causal de dicha detección. Daniel Wegner, a quien discuto más abajo (sección 3.2), parece defender una posición de este tipo. 
Epifenomenalismo. Los estados mentales conscientes de las personas no son causalmente relevantes para la producción de sus acciones, sino que sólo acompañan a, o son subproductos de, aquellos procesos que sí lo son. Es decir, los estados mentales conscientes son meros epifenómenos.

Uno de los dos argumentos principales a favor de la tesis del epifenomenalismo es el argumento reduccionista. El núcleo del argumento es éste: puesto que las ciencias de la mente muestran que los estados mentales conscientes son instanciados por procesos neuronales, podemos concluir que las verdaderas causas de las acciones son estos procesos y no los estados conscientes mismos. Y puesto que, para efectos de las atribuciones de responsabilidad, las personas se identifican con sus estados mentales conscientes (con sus deseos, planes, intenciones, creencias, etcétera), podemos concluir también que las personas no son la causa de sus acciones y, por tanto, no son responsables por ellas. ${ }^{31}$

Joshua Greene y Jonathan Cohen emplean este argumento en el influyente artículo en el que presentan su versión del reto global a la responsabilidad jurídica. Ellos afirman que, si bien el derecho penal se concentra exclusivamente en la cuestión de si el acusado poseía las capacidades racionales requeridas para haber actuado correctamente, las intuiciones ordinarias acerca de las atribuciones de responsabilidad se basan en algo distinto, a saber: "Lo que la gente realmente quiere saber es si el acusado, y no otra cosa, es responsable por el crimen, donde esta otra cosa podría ser el cerebro del acusado, sus genes o sus circunstancias". ${ }^{32}$ Sin embargo, continúan, es muy plausible pensar que en un futuro no muy lejano la neurociencia será capaz de mostrar vívidamente que cualquier evento mental -incluyendo las decisiones - que, en nuestra ignorancia actual, atribuimos a la persona misma, es en realidad el resultado de procesos neuronales. Para ilustrar este punto, presentan el siguiente ejemplo:

Imagina que ves una película de tu cerebro eligiendo entre una sopa y una ensalada. El programa de computadora pinta de rojo a

31 Diferentes variantes de este argumento se hallan en Greene, Joshua y Cohen, Jonathan, op. cit.; Dawkins, Richard, op. cit.; Cashmore, Anthony, op. cit.

32 Greene, Joshua y Cohen, Jonathan, op. cit., p. 1780, énfasis añadido. 
las neuronas que están a favor de la sopa y de azul a las neuronas a favor de la ensalada. La película te permite rastrear las relaciones de causa-efecto entre neuronas individuales... hasta el punto crucial en el que las neuronas azules vencen a las rojas, tomando el control de tu corteza premotora y causando que tú digas: "Quiero la ensalada, por favor". ${ }^{33}$

Hay dos maneras de interpretar este ejemplo y su relevancia para las atribuciones de responsabilidad. Por un lado, lo que el ejemplo sugiere es que la neurociencia será capaz de mostrar vívidamente que todas nuestras decisiones son productos causales de otros eventos (en este caso, eventos neuronales) y, por lo tanto, será capaz de mostrar que carecemos de voluntad libre concebida de cierta manera (como causa incausada, digamos). Por otro lado, lo que el ejemplo sugiere es que la neurociencia será capaz de mostrar vívidamente que nuestros procesos mentales conscientes (tales como la evaluación de razones a favor de comer sopa o ensalada) no son la causa real de nuestras acciones sino meros efectos de ciertos procesos neuronales (el "combate" entre las neuronas rojas y azules) y, por tanto, será capaz de mostrar que el verdadero responsable de las acciones no es la persona sino su cerebro.

Si bien Greene y Cohen no distinguen entre ambas interpretaciones, es claro que sólo la segunda de ellas es potencialmente relevante para la responsabilidad jurídica. Si el ejemplo se interpreta del primer modo resulta irrelevante porque, aun concediendo que todas nuestras decisiones conscientes están causalmente determinadas por otros eventos, ello no implica que dichas decisiones (y otros estados mentales conscientes) no estén ellas mismas causalmente involucradas en la producción de la acción. Esto último es todo lo que el supuesto de causación mental exige; no exige que nuestras decisiones sean producto de una voluntad que es causa incausada. Por otro lado, si el ejemplo se interpreta del segundo modo sí sería potencialmente relevante para la responsabilidad jurídica puesto que atacaría directamente el supuesto de causación mental: ciertos procesos neuronales, y no los estados mentales conscientes que supervienen en ellos, serían las verdaderas causas de nuestras acciones.

33 Ibidem, p. 1781, énfasis añadido. 
Ahora bien, ¿es convincente la segunda interpretación del ejemplo? No lo es, pues aun concediendo que en un futuro será posible rastrear minuciosamente los procesos neuronales que implementan la toma de decisiones, ello no implicaría que los estados mentales conscientes que las preceden (por ejemplo, la valoración de razones pro y contra), así como las decisiones mismas, sean meros epifenómenos. ${ }^{34}$ Sostener lo contrario es un ejemplo de lo que podemos llamar "la falacia reduccionista", a saber, pensar que, puesto que $\mathrm{X}$ superviene en, o es instanciado por, Y, entonces todos los poderes causales que usualmente atribuimos a $X$ son en realidad poderes causales de Y. Este razonamiento es claramente incorrecto. Como lo ejemplifica Eddy Nahmias, "el hecho de que los pájaros están compuestos de quarks no significa que sus alas no juegan un papel causal en su vuelo". ${ }^{35}$ De igual manera, el hecho de que las decisiones y demás estados mentales conscientes posean correlatos neuronales no significa que aquéllas no juegan un papel causal en la producción de las acciones.

Podemos conceder, pues, que la neurociencia será capaz de explicar con cada vez mayor detalle cómo las decisiones y otros estados mentales conscientes son instanciados en el cerebro sin conceder al mismo tiempo que esto será evidencia de que aquéllas y éstos son

34 Por lo tanto, Morse concede demasiado al decir que, si el escenario del ejemplo se volviera realidad, "Greene y Cohen estarían probablemente en lo cierto en que la noción de responsabilidad desaparecería, porque la mayoría creería que fue el cerebro el que hizo cierta acción, no el agente, y no atribuimos responsabilidad moral a los cerebros" (Morse, Stephen, "Determinism and the Death of Folk Psychology...", cit., p. 22). Por el contrario, la respuesta adecuada al ejemplo de Greene y Cohen es, por un lado, sostener que, aun si la mayoría de la gente creyera que fue el cerebro y no la persona quien realizó cierta acción, de ello no se seguiría que el derecho debería tomar esta (equivocada) creencia seriamente, y, por otro, cuestionar incluso la suposición de que dicha creencia surgiría en primer lugar. ¿Por qué no suponer que la gente interpretaría dichos descubrimientos científicos como evidencia de cómo las decisiones que tomamos son instanciadas en el cerebro, análogamente al modo en que nuestras acciones voluntarias son instanciadas por complicados procesos musculares?

35 Nahmias, Eddy, "Is Free Will and Illusion? Confronting Challenges from the Modern Mind Sciences", en Sinnott-Armstrong, Walter (ed.), Moral Psychology, vol. 4: Free Will and Moral Responsibility, Cambridge, MIT Press, 2014, p. 11. 
superfluos a la hora de explicar (causalmente) la conducta de las personas. En otras palabras, el mero hecho de que el cerebro implemente los procesos mentales conscientes no quiere decir que éstos sean causalmente ociosos. Así pues, el argumento reduccionista no logra establecer la tesis del epifenomenalismo y, por tanto, deja intacto el supuesto de causación mental que es central en el derecho.

\section{El argumento modular}

El segundo argumento a favor de la tesis del epifenomenalismo presenta un reto mucho más serio al supuesto de causación mental. Siguiendo a Nahmias, lo llamo "el argumento modular". ${ }^{36}$ A diferencia del argumento reduccionista, el argumento modular no se contenta con señalar que los estados mentales conscientes que acompañan a las acciones son implementados por procesos neuronales, sino que va más allá al presentar evidencia que supuestamente muestra que estos procesos neuronales son, ellos mismos, causalmente ineficaces en la producción de las acciones. Una manera de mostrar que éste es el caso es apelar a evidencia que sugiere que el módulo del cerebro encargado de producir los estados mentales conscientes que suelen acompañar a las acciones y que, aparentemente, son causa de éstas, es distinto del módulo que realmente produce las acciones (de ahí el nombre "argumento modular"). El proponente más destacado de este argumento es Daniel Wegner. A continuación bosquejo y evalúo críticamente su propuesta.

En su libro The Illusion of Conscious Will, Wegner sostiene que la voluntad consciente, entendida como la experiencia ordinaria de sentir que uno mismo ha causado los movimientos corporales propios, es una ilusión, en el sentido de que dicha experiencia no es, como usualmente se supone, un indicador de que la persona misma -identificada aquí con su conciencia - sea de hecho la que causa y controla las acciones. ${ }^{37}$ En otras palabras, si bien la experiencia

36 Ibidem, p. 12.

37 Wegner, Daniel, The Illusion of Conscious Will, Cambridge, MA, MIT Press, 2002. 
de ser el autor de nuestras acciones suele acompañar a éstas, la experiencia misma, incluyendo los estados mentales concomitantes como creencias, deseos e intenciones, no está causalmente involucrada en la producción de las acciones. Así pues, la voluntad consciente sería un mero epifenómeno. ${ }^{38}$

Para sustentar esta sorprendente afirmación, Wegner ofrece lo que él llama "la teoría de la causación mental aparente". De acuerdo con ella, la voluntad consciente no es la causa de las acciones sino el efecto de una serie de mecanismos interpretativos que ligan los pensamientos conscientes de la persona con sus movimientos corporales. En particular, la experiencia de autoría emerge cuando los pensamientos de la persona (relacionados con sus deseos, creencias e intenciones) satisfacen las siguientes tres características: 1) ocurren durante un intervalo adecuado antes de la acción; 2) son consistentes semánticamente con la acción que tiene lugar, y 3) no hay una explicación alternativa de qué pudo haber causado dicha acción. Cuando los pensamientos satisfacen estos requisitos de prioridad, consistencia y exclusividad, la persona experimenta la sensación de autoría sobre sus movimientos. Por ejemplo: deseo una bebida y creo que puedo obtenerla si me aproximo a la máquina expendedora (prioridad); a continuación me observo a mí mismo caminando precisamente hacia allá (consistencia) y, finalmente, la única explicación que tengo a la mano de por qué estoy haciendo esto apela justamente a mis deseos y creencias conscientes (exclusividad). En consecuencia, experimento la sensación de autoría sobre la acción que observé: caminar a la máquina expendedora y comprar una bebida. Sin embargo, dado que esta experiencia es, según la teoría, producida por una serie de procesos interpretativos que nada tienen que ver con los mecanismos causales que de hecho producen las acciones, el nombre "causación mental aparente" resulta apto: dicha experiencia nos hace creer que nuestros pensamientos causan nuestras acciones, pero éste no es el caso.

38 Para Wegner (ibidem, cap. 9), ello no implica que la experiencia de autoría de las acciones sea irrelevante. Al contrario, él piensa que esta experiencia es crucial para organizar las relaciones con otras personas y para construir la identidad personal. Sin embargo, dicha experiencia sí es, de acuerdo con él, un epifenómeno en el sentido indicado: ella no está involucrada en la producción de nuestras acciones. 
La propuesta de Wegner, así como la evidencia empírica que aduce a su favor, son complejas y no pretendo hacerles justicia aquí. ${ }^{39}$ Me limito a presentar dos objeciones generales a su teoría de la causación mental aparente y a las consecuencias que pretende derivar de ella.

La primera objeción es acerca de la interpretación que hace Wegner de la evidencia que, según él, demuestra que la experiencia de autoría es ilusoria. Esta evidencia proviene mayormente de experimentos que muestran que dicha experiencia puede producirse artificialmente (o inhibirse artificialmente) siempre y cuando los principios de prioridad, consistencia y exclusividad se vean satisfechos (o bloqueados). Por ejemplo, en un experimento similar a un ejercicio de pantomima, los sujetos sienten que controlan unas manos que no son suyas pero que están posicionadas exactamente donde estarían las propias, siempre y cuando escuchen las instrucciones que el experimentador dicta en voz alta a quien de hecho las mueve (y quien se encuentra oculto). ${ }^{40}$ En este caso, la experiencia de autoría se produce artificialmente gracias a que los pensamientos de los sujetos -inculcados por las instrucciones del experimentador-satisfacen los tres principios citados. A la inversa, el fenómeno de la "comunicación facilitada", relacionado con una terapia demostradamente falsa en la que una persona autista supuestamente tecleaba ciertos mensajes con ayuda de un facilitador quien creía sinceramente que era el paciente y no él quien realizaba la acción, muestra que la experiencia de autoría puede bloquearse artificialmente (en el caso del facilitador) si uno de los principios que la producen (aquí el de exclusividad) no se ve satisfecho. ${ }^{41}$

39 Véase Pockett, Susan, Banks, William y Gallagher, Shaun (eds.), Does Consciousness Cause Behavior?, Cambridge, MA, MIT Press, 2006, para una interesante colección de artículos que discuten la obra de Wegner y la de otros teóricos afines, como Benjamin Libet.

40 Wegner, Daniel, Sparrow, Betsy y Winerman, Lea, "Vicarious Agency: Experiencing Control over the Movements of Others", Journal of Personality and Social Psychology, vol. 86, núm. 6, 2004, pp. 838-848.

41 Wegner, Daniel, Fuller, Valerie y Sparrow, Betsy, “Clever Hands: Uncontrolled Intelligence in Facilitated Communication", Journal of Personality and Social Psychology, vol. 85, núm. 1, 2003, pp. 5-19. 
Wegner presenta muchos casos más de disociación entre la experiencia de agencia y la agencia misma, los cuales, piensa él, claramente demuestran que dicha experiencia es en general ilusoria. ${ }^{42}$ El problema, sin embargo, es que del hecho de que la experiencia de agencia en ocasiones no refleje verdadero control agencial no se sigue que ordinariamente no lo hace. A la inversa, del hecho de que el control agencial pueda darse sin la experiencia de agencia (como en el caso de la comunicación facilitada) no se sigue que, por regla general, no vayan de la mano. Más importante aún, tampoco se sigue que, cuando van de la mano, los estados conscientes de la persona - los cuales contribuyen a la sensación de agencia- no sean causalmente relevantes para el control agencial. ${ }^{43}$ Así pues, bien puede ser el caso que ordinariamente suceda lo siguiente: ciertos pensamientos conscientes de la persona de hecho causan sus acciones y, además, puesto que dichos pensamientos satisfacen los requisitos de prioridad, consistencia y exclusividad, la persona experimenta la acción como producto suyo. Si esto es así, entonces lo que la teoría de Wegner en realidad consigue es, por un lado, explicar cómo se produce ordinariamente la experiencia (y no la ilusión) de autoría y, por otro, mostrar que los mecanismos que la producen son falibles, es decir, que están sujetos al tipo de distorsiones ilustradas por los experimentos descritos arriba. Sin embargo, que dichos mecanismos sean falibles no significa que, en general, no sean fidedignos. ${ }^{44}$

Confrontado con esta objeción, Wegner respondería que aquello que la evidencia indudablemente muestra es que la experiencia de autoría y las acciones mismas son producidas por módulos cerebrales independientes. Si ello no fuera así, sería difícil explicar la divergencia observada en los experimentos entre experiencia de autoría y control agencial. Pero - continuaría Wegner - si aceptamos que el módulo que genera la experiencia de autoría es diferente del mó-

42 Wegner, Daniel, “The Illusion..., cit.

43 Nahmias, Eddy, "When Consciousness Matters: A Critical Review of Daniel Wegner's The Illusion of Conscious Will”, Philosophical Psychology, vol. 15, núm. 4, pp. 527-541, 2002, p. 533.

44 Bayne, Tim, "Phenomenology and the Feeling of Doing: Wegner on the Conscious Will”, en Pockett, Susan et al. (eds.), Does Consciousness Cause Behavior?, Cambridge, MA, MIT Press, 2006, p. 178. 
CIENCIAS DE LA MENTE Y RESPONSABILIDAD JURÍDICA...

dulo que de hecho produce las acciones, entonces debemos aceptar que el agente no es la causa de éstas, lo cual es otra manera de mostrar que la voluntad consciente es ilusoria. Wegner parece tener esta línea de respuesta en mente cuando escribe lo siguiente:

La creación de nuestra sensación de agencia es sumamente importante para una gran cantidad de procesos personales y sociales, aun cuando este agente percibido no sea la causa de la acción... Al realizar estas inferencias [que producen la sensación de agencia], obtenemos la imagen de un agente virtual, de una mente que aparentemente guía la acción. ${ }^{45}$

Mi segunda objeción a Wegner es que éste se equivoca al concluir, a partir de la aparente modularidad de los mecanismos que producen la experiencia de agencia y las acciones mismas, que los agentes no son la causa de éstas. En efecto, del hecho de que la experiencia de agencia sea producida por un módulo distinto del módulo que causa las acciones no se sigue que la autoría de éstas no pueda ser atribuida a la persona misma. A este respecto, resulta crucial hacer la distinción entre la experiencia de agencia y la agencia misma (o entre la experiencia de voluntad consciente y la voluntad misma). Con base en esta distinción, podemos conceder a Wegner que la experiencia de agencia no es la causa de las acciones sino que, tal como él sostiene, dicha experiencia es producto de ciertos mecanismos interpretativos que son distintos de los mecanismos causales que producen el comportamiento. Sin embargo, ello no nos impide identificar la agencia misma con estos mecanismos causales (o con un subconjunto de ellos). Por ejemplo, una propuesta plausible es identificar al agente con un mecanismo que detecta y responde a consideraciones racionales. ${ }^{46}$ Cuando este mecanismo es causalmente efectivo en la producción de la acción, entonces estamos autorizados a atribuirla a la persona como un producto suyo. ${ }^{47}$ Además, dado

45 Wegner, Daniel, “Who Is the Controller of Controlled Processes?", en Hassin, Ran et al. (eds.), The New Unconscious, Oxford, Oxford University Press, 2006, p. 30, énfasis añadido.

46 Véase Fischer, John y Ravizza, Mark, Responsibility and Control: A Theory of Moral Responsibility, Cambridge, Cambridge University Press, 1998.

47 Esta propuesta - la firme separación de la experiencia de agencia de la agen- 
que es razonable asumir que un mecanismo como el descrito opera, al menos parcialmente, a través de estados mentales conscientes (por ejemplo a través de la valoración de consideraciones en pro y en contra de cierto curso de acción), podemos sostener que la conciencia del sujeto sí es causalmente relevante en la producción de la acción. De este modo, podemos reconciliar la modularidad a la que Wegner alude con la suposición de sentido común de que los agentes mismos son causa de sus acciones.

En suma, ni la teoría de la causación mental aparente que defiende Wegner, ni la evidencia que ofrece a favor de ella, muestran que la tesis del epifenomenalismo es correcta. Por lo tanto, el argumento modular tampoco socava el presupuesto de causación mental que es piedra angular de la responsabilidad moral y jurídica. ${ }^{48}$

\section{EL RETO LOCAL}

\section{La falsedad del supuesto de capacidades generales}

Argumenté en la sección anterior que los dos argumentos principales que componen el reto global fallan. Si ello es así, entonces la

cia misma- permite explicar por qué ciertas acciones, como por ejemplo las llamadas skilled actions que lleva a cabo un deportista profesional o un cirujano, pueden ser atribuidas a la persona aun cuando ella no experimente la sensación de autoría sobre las mismas y se perciba, al contrario, como un mero espectador de ellas. (Wegner, Daniel, "Who Is the Controller...", cit., p. 29, apela a este fenómeno en apoyo de su teoría). Dado que estas acciones indudablemente son sensibles a razones, podemos suponer que los mecanismos que las produjeron son precisamente aquellos que respaldan la atribución de ciertos movimientos corporales a un agente como propios. El hecho de que la experiencia de agencia o autoría pueda estar ausente en dichos casos no afecta en nada la corrección de la atribución.

48 Más recientemente, Paul Davies (Davies, Paul, op. cit.) ha empleado la teoría de Wegner para atacar el supuesto de causación mental en el derecho. En particular, Davies sostiene que dicha teoría falsea la suposición básica del derecho penal de que podemos distinguir fidedignamente cuáles acciones son voluntarias y cuáles no. Carezco de espacio para discutir en detalle el artículo de Davies pero, si mis objeciones a Wegner son adecuadas, ellas le restan toda plausibilidad a la tesis central que defiende aquél. 
evidencia actual proveniente de las ciencias de la mente no apoya la afirmación de que el derecho - y en particular el derecho penaldebe ser radicalmente revisado. Ello no quiere decir, sin embargo, que las ciencias de la mente no tengan nada que enseñarnos acerca de la adecuación empírica de la psicología de sentido común empleada en el derecho. Por el contrario, como argumentaré en esta sección y la siguiente, ciertos descubrimientos acerca de los límites de nuestras capacidades racionales sugieren que la psicología de sentido común y la concepción de la persona racional asociada con ella deben ser localmente revisadas y, junto con ambas, ciertas disposiciones jurídicas que pasan por alto dichos límites deben ser revisadas también. ${ }^{49}$

En la subsección 2.2 sostuve que uno de los supuestos básicos de la concepción de la persona racional empleada en el derecho penal es el supuesto de capacidades racionales generales. Como expliqué ahí, éste es el supuesto de que las capacidades cognitivas y volitivas requeridas para percatarse de, y actuar con base en, razones son estables a través de diferentes contextos y que aquellos contextos en los que no lo son (es decir, aquellos contextos en los que dichas capacidades no funcionan como deberían) coinciden con las excusas y exenciones reconocidas por la moral y el derecho. Este supuesto apoya, por un lado, la convicción de que en ausencia de factores como demencia o coerción cualquier adulto normal siempre tiene la posibilidad de reconocer cuáles son sus obligaciones morales y jurídicas ${ }^{50}$ y actuar en consecuencia; y apoya, por otro, la convicción

49 Nicole Vincent (Vincent, Nicole, "Legal Responsibility Adjudication and the Normative Authority of the Mind Sciences", Philosophical Explorations, vol. 14, núm. 3, pp. 315-331, 2011) y Leora Dahan-Katz (Dahan-Katz, Leora, "The Implications of Heuristics and Biases Research on Moral and Legal Responsibility", en Vincent, Nicole (ed.), Neuroscience and Legal Responsibility, Oxford, Oxford University Press, 2013, pp. 135-156) comparten esta visión optimista acerca de la relación entre el derecho y las ciencias de la mente, pues ambas sugieren distintas maneras en las que los descubrimientos de éstas pueden ayudar con las tareas propias de aquél. Sin embargo, ni Vincent ni Dahan-Katz discuten la evidencia situacionista en la que se basa mi argumento. Para otra posición optimista véase Montemayor, Carlos y Cáceres, Enrique, op. cit.

50 Me refiero en particular a obligaciones jurídicas relacionadas con el derecho penal y, más específicamente, a obligaciones jurídicas ancladas en obligaciones 
de que cualquier adulto que viole algunas de estas obligaciones, y carezca además de una excusa moral o jurídicamente reconocida, es moral y/o jurídicamente responsable por dicha violación.

A continuación argumentaré, con base en evidencia proveniente de la psicología social situacionista, que el supuesto de capacidades racionales generales es falso: lejos de ser estables a través de un amplio rango de circunstancias, las capacidades para detectar consideraciones normativas relevantes y actuar en consecuencia están indexadas a contextos específicos de acción. Sostendré además que las circunstancias que afectan de manera significativa a la agencia responsable van más allá de las excusas y exenciones moral y jurídicamente reconocidas. Me enfocaré en particular en evidencia que muestra que presiones situacionales en apariencia nimias conducen a muchos sujetos a obviar demandas altruistas básicas o incluso a cometer acciones moralmente aberrantes, independientemente de cuáles sean sus convicciones morales. Buscaré mostrar que dichas presiones situacionales interfieren con el ejercicio adecuado de las capacidades racionales relevantes para las atribuciones de responsabilidad y son, por tanto, similares a las excusas moral y jurídicamente reconocidas. Describo a continuación de modo sucinto el conjunto de evidencia empírica en el que se basan estas afirmaciones para después mostrar su relevancia para el derecho.

\section{La evidencia situacionista}

La psicología social situacionista es una tradición en psicología experimental que enfatiza la importancia de factores situacionales para explicar y predecir la conducta de las personas y que sostiene, al mismo tiempo, que las disposiciones y rasgos de carácter individuales tienen comparativamente menor relevancia explicativa y

morales como por ejemplo la obligación de no dañar a inocentes o la obligación de prestar ayuda a otros cuando ello no resultaría muy oneroso para uno mismo. Existen desde luego muchas disposiciones jurídicas que son relativamente difíciles de detectar para una persona ordinaria, por ejemplo disposiciones relacionadas con los cada vez más abigarrados códigos fiscales. 
predictiva. Las tesis centrales del situacionismo, todas ellas respaldadas por evidencia empírica sustancial, son las siguientes tres. ${ }^{51}$

a. El poder y sutileza de las situaciones. La tesis básica del situacionismo es que factores situacionales aparentemente nimios - tales como presiones de tiempo, ruidos potentes, olores agradables, la presencia de otras personas, triviales golpes de buena suerte, órdenes de parte de un experimentador, etcétera- tienen efectos sustanciales sobre el comportamiento de las personas, incluyendo comportamiento moralmente relevante. Lo que resulta especialmente sorprendente de la evidencia situacionista es la desproporción entre el input situacional y el output conductual. Por ejemplo, Isen y Levin encontraron que colocar una moneda en la ranura de devoluciones de una cabina telefónica tuvo un efecto sustancial en la propensión de las personas a ayudar a alguien a recoger unos papeles: 87 por ciento de los sujetos ayudó tras encontrar la moneda, mientras que sólo 4 por ciento ayudó tras no encontrar nada. ${ }^{52}$ En otro experimento clásico, Darley y Batson descubrieron que la principal variable que explicaba la diferencia entre un grupo de seminaristas que ayudó a una persona aparentemente enferma y otro grupo que no lo hizo fue la prisa que tenían los miembros de cada uno por completar una tarea asignada por el experimentador: 63 por ciento de los sujetos ayudó sin prisa contra 10 por ciento con prisa..$^{53}$ Por su parte, Latané y Darley, descubridores del llamado "efecto del espectador" (bystander effect), encontraron que la propensión de las personas a prestar ayuda en situaciones de emergencia disminuye considerablemente por la mera presencia de otras personas, sobre todo si éstas se muestran impasibles. ${ }^{54}$ En una de las variantes del paradigma experimental, sólo 7 por ciento de los sujetos ayudó a la supuesta

51 Ross, Lee y Nisbett, Richard, The Person and the Situation: Perspectives of Social Psychology, Nueva York, McGraw-Hill, 1991, pp. 8-13.

52 Isen, Alice y Levin, Paula, "Effect of Feeling Good on Helping", Journal of Personality and Social Psychology, vol. 21, núm. 3, 1972, pp. 384-388.

53 Darley, John y Batson, Daniel, "From Jerusalem to Jericho: A Study of Situational and Dispositional Variables in Helping Behavior", Journal of Personality and Social Psychology, vol. 27, núm. 1, 1973, pp. 100-108.

54 Latané, Bibb y Darley, John, The Unresponsive Bystander: Why Doesn't He Help?, Nueva York, Appleton-Century Crofts, 1970. 
víctima cuando un cómplice del experimentador en actitud impasible se hallaba presente contra 70 por ciento cuando los sujetos se hallaban solos. ${ }^{55}$ Finalmente, en los perturbadores experimentos de Milgram sobre obediencia a la autoridad, en promedio 65 por ciento de los sujetos administraron supuestos electrochoques potencialmente mortales a un cómplice del experimentador siguiendo las instrucciones de éste, quien, firme pero educadamente, los alentaba a seguir con la prueba que presuntamente tenía por objeto averiguar la relación entre castigo y aprendizaje. ${ }^{56}$ En todos estos casos, el aparentemente insignificante factor situacional bajo estudio - trivial, buena suerte, prisa, presencia de otras personas, órdenes de un experimentador - explicaba en buena medida las dramáticas diferencias observadas en el comportamiento de los sujetos. ${ }^{57}$

b. La comparativa irrelevancia explicativa y predictiva de las diferencias individuales. La tesis de que las diferencias en el comportamiento de los sujetos en estos experimentos se deben a factores situacionales y no a rasgos de carácter se ve reforzada por la poca o nula correlación entre dichos rasgos y la conducta observada. Como parte de los experimentos, los sujetos son sometidos a pruebas estándar en psicología (usualmente cuestionarios) para detectar ciertos rasgos de personalidad que pudieran estar implicados en el com-

55 Latané, Bibb y Rodin, Judith, "A Lady in Distress: Inhibiting Effects of Friends and Strangers on Bystander Intervention", Journal of Experimental Social Psychology, vol. 5, núm. 2, 1969, pp. 189-202.

56 Milgram, Stanley, "Behavioral Study of Obedience", Journal of Abnormal and Social Psychology, vol. 67, núm. 4, 1963, pp. 371-8.

57 Cabe resaltar que ésta es una muestra minúscula de la evidencia en la que se sustenta el situacionismo. Si bien estos experimentos son los más conocidos, sus resultados han sido ampliamente replicados por muchos otros, en particular por lo que toca al efecto del espectador (vuelvo a este último un poco más abajo en el texto). Nada de esto implica, desde luego, que no existan críticas importantes al paradigma situacionista. Véase por ejemplo Sabini, John, Siepmann, Michael y Stein, Julia "The Really Fundamental Attributional Error in Social Psychological Research," Psychological Inquiry 12, 2000, pp. 1-15; Sabini, John y Silver, Maury "Internal and External Causes of Behavior," International Journal of Moral and Social Studies 2, 1987, pp. 11-23. Sin embargo, como señalo más abajo (nota 70), el situacionismo no es la única fuente de evidencia empírica que apoya la tesis que defiendo en este artículo. 
portamiento de interés. Los experimentadores controlan también por variables sociodemográficas como sexo, edad, nivel educativo y de ingresos. El resultado usual es que tanto las variables de personalidad como las variables sociodemográficas resultan de escaso valor explicativo y predictivo en relación con el comportamiento que se busca estudiar, lo cual realza la importancia de las variables situacionales. Dos consecuencias importantes se extraen de este descubrimiento. Primero, dada la comparativa fuerza explicativa y predictiva de las situaciones frente a las disposiciones individuales, se concluye que la consistencia conductual de las personas a través de distintos tipos de situaciones es baja. En el caso del comportamiento altruista, por ejemplo, la inferencia es que las personas no prestan ayuda de manera consistente aun cuando la asistencia requerida sea poco costosa para el sujeto y sin importar mucho las disposiciones altruistas individuales, sino que más bien esta clase de comportamiento varía en un grado importante de acuerdo con ciertas características situacionales claramente identificables. Segundo, se concluye que las personas suelen responder de manera relativamente uniforme a las situaciones que enfrentan, independientemente de sus diferencias en cuanto a disposiciones y rasgos de carácter. ${ }^{58}$

c. El error fundamental de atribución. La tercera tesis del situacionismo es que las personas, al ignorar tanto el poder de las situaciones como la relativa irrelevancia de las diferencias caracterológicas individuales, suelen cometer el "error fundamental de atribución" al explicar y predecir el comportamiento de otros. Este error consiste "en pasar por alto las causas situacionales de las acciones y enfatizar las causas disposicionales"; ${ }^{59}$ en otras palabras, las personas suelen sobreestimar la contribución de los rasgos de personalidad en la producción del comportamiento y, a la vez, suelen subestimar la contribución de factores situacionales. El error fundamental de atribución se manifiesta con particular agudeza cuando el comportamiento en cuestión es atípico, por ejemplo cuando una persona en apariencia normal no ayuda a otra en una situación crítica en la cual el costo de ayudar es bajo. En tales circunstancias

59 Ibidem, p. 79. 
la gente suele no reconocer que las acciones y los resultados, en particular los que son sorprendentes o atípicos, no son indicativos de disposiciones únicas de parte del agente sino, más bien, indicativos de los factores situacionales objetivos a los que el agente se enfrentó y de las interpretaciones subjetivas que éste hizo de aquellos factores. En efecto, la gente rápidamente reinterpreta a la persona (esto es, infiere que es diferente de las personas ordinarias) y muy rara vez reinterpreta la situación, esto es, rara vez infiere que la interpretación original que se hizo de la situación es errónea o, cuando menos, significativamente diferente de la del agente. ${ }^{60}$

Como explicaré en la subsección 4.3, estas tres tesis -el poder de las situaciones, la comparativa irrelevancia de las diferencias individuales y el error fundamental de atribución-, así como la evidencia empírica en la que se sustentan, constituyen un reto muy importante a las prácticas de atribución de responsabilidad moral y jurídica. Antes de pasar a ello, sin embargo, ahondaré en el efecto del espectador aludido antes, debido a que éste será central en la discusión sobre la relevancia del situacionismo para el derecho que me ocupará en la sección 5.

\section{El efecto del espectador}

Mencioné arriba que Latané y Darley descubrieron que la propensión de las personas a prestar ayuda en emergencias disminuye considerablemente por la mera presencia de otras personas, sobre todo si éstas reaccionan pasivamente ante el suceso. ${ }^{61} \mathrm{~A}$ este fenómeno se le conoce como "inhibición social de la intervención del espectador" o, más brevemente, como "efecto del espectador". ${ }^{22}$ Latané y Dar-

60 Ibidem, pp. 12-3.

61 Latané, Bibb y Darley, John, op. cit.

62 Este fenómeno es ampliamente considerado como uno de los descubrimientos más robustos (es decir, mejor confirmados por una multitud de estudios) de la psicología social. Véase por ejemplo el reciente meta-análisis de la evidencia en Fischer, Peter et al., "The Bystander-Effect: A Meta-Analytic Review of Bystander Intervention in Dangerous and Non-Dangerous Emergencies", Psychological Bulletin, vol. 137, núm. 4, 2011, pp. 517-537, el cual confirma la realidad del efecto del espectador. 
CIENCIAS DE LA MENTE Y RESPONSABILIDAD JURÍDICA...

ley identificaron dos procesos psicológicos que explican el efecto del espectador: la difuminación de la responsabilidad y la ignorancia plural. La difuminación de la responsabilidad ocurre cuando la sensación de responsabilidad personal para intervenir ante un suceso disminuye debido a la presencia de otras personas; en el caso que nos ocupa, mientras más personas sean testigos de una emergencia, menos responsabilidad sentirá cada una de ellas por hacer algo al respecto. La ignorancia plural ocurre cuando la ambigüedad de la situación - ya sea acerca de la gravedad de la emergencia o acerca de cuál es la respuesta más apropiada a ésta- hace que las personas busquen pistas en sus reacciones mutuas para definir qué tan grave es la aparente emergencia y qué reacción es apropiada. En la medida en que los demás parecen reaccionar pasiva o despreocupadamente, el sujeto tiende a reinterpretar la situación de modo que la no intervención parece la opción adecuada, ya sea porque aparentemente no se trata de una situación grave o porque resulta más prudente no intervenir. Cuando la difuminación de la responsabilidad y la ignorancia plural se combinan, la inacción de los sujetos se potencia: nadie se siente obligado a ser el primero en intervenir y, al mismo tiempo, la pasividad del grupo es interpretada por sus miembros como una señal de que no es necesario hacerlo. Nótese la naturaleza situacionista de esta explicación: en lugar de apelar a rasgos de carácter tales como apatía, indiferencia o egoísmo, se invocan factores situacionales - la presencia de otras personas y sus reacciones ante la emergencia- para explicar el comportamiento no altruista.

Además de la difuminación de la responsabilidad y la ignorancia plural, otro factor situacional que ha mostrado ser relevante para explicar el comportamiento no altruista tiene que ver con las características de la víctima. Específicamente, hay evidencia de que una persona tiene sustancialmente menos posibilidades de ser socorrida en comparación con otra que sufre exactamente el mismo percance si la primera sangra como consecuencia de su accidente, si padece una desfiguración facial o si se encuentra en estado de ebriedad. ${ }^{63}$

63 Piliavin, Irving, Rodin, Judith y Piliavin, Jane, “Good Samaritanism: An Underground Phenomenon?", Journal of Personality and Social Psychology, vol. 13, núm. 4, 1969, pp. 289-299; Piliavin, Jane y Piliavin, Irving, “Effect of Blood on Reaction 
En suma, a la luz de la evidencia disponible podemos concluir que la inacción de los sujetos ante una emergencia será más frecuente cuando se conjuntan los tres factores situacionales descritos, esto es, cuando: a) la responsabilidad personal se diluye debido a la presencia de dos o más personas en el lugar de la emergencia; b) la ambigüedad de la situación provoca ignorancia plural acerca de cuál es la respuesta adecuada; y c) la persona necesitada de ayuda padece un estigma físico o moral. En la sección 5 estudiaremos el caso real de una emergencia que conjuntaba estos tres factores y en el que las personas que no prestaron ayuda fueron sancionadas por la autoridad. Plantearé ahí la pregunta de si la evidencia acerca del efecto del espectador es relevante para determinar si dichas personas eran moral y/o jurídicamente responsables por su omisión y, por tanto, si la sanción que les fue impuesta era apropiada o no.

\section{Situacionismo y responsabilidad}

¿Qué relevancia tiene la psicología social situacionista para la teoría de la responsabilidad jurídica y moral? Sostengo que es relevante por dos razones principales. Primero, la evidencia situacionista muestra que el supuesto de capacidades racionales generales es falso, dado que las capacidades relevantes para las atribuciones de responsabilidad - las capacidades para detectar y responder a consideraciones normativas- no son estables a través de distintas circunstancias sino que, por el contrario, están indexadas a contextos específicos de acción. Segundo, dicha evidencia sugiere que las atribuciones ordinarias de responsabilidad (moral y jurídica) son insuficientemente sensibles a la influencia de factores situacionales sobre el comportamiento. Explicaré ambos puntos en las subsecciones respectivas.

to a Victim", Journal of Personality and Social Psychology, vol. 23, núm. 3, 1972, pp. 353-361; Piliavin, Irving, Piliavin, Jane y Rodin, Judith, "Costs, Diffusion, and the Stigmatized Victim", Journal of Personality and Social Psychology, vol. 32, núm. 3, 1975, pp. 429-438. 
CIENCIAS DE LA MENTE Y RESPONSABILIDAD JURÍDICA...

\section{Capacidades generales vs. capacidades indexadas a circunstancias}

La evidencia situacionista muestra que, lejos de ser estables a través de un amplio rango de circunstancias, las capacidades para detectar consideraciones normativas relevantes y actuar en consecuencia están indexadas a contextos específicos de acción. Ello implica dos cosas importantes: primero, que las personas son capaces de detectar y responder a cierta clase de consideraciones en cierto tipo de circunstancias; segundo, que no podemos inferir del hecho de que una persona detectó y respondió a cierta clase de consideraciones en cierto tipo de circunstancias que es razonable esperar que la persona será capaz de hacer lo propio en una situación diferente. En otras palabras, aquello que es razonable esperar de las capacidades de las personas para detectar y responder a consideraciones moral y jurídicamente relevantes varía de acuerdo con las consideraciones y situaciones de las que se trate. ${ }^{64}$

El situacionismo provee amplia evidencia para sustentar ambas afirmaciones. Piénsese, por ejemplo, en los experimentos de Milgram sobre obediencia. ${ }^{65}$ Los sujetos que, según lo creían ellos mismos, aplicaron el máximo castigo de 450 voltios a otra persona en una supuesta prueba de aprendizaje simplemente porque el experimentador así se los exigía fueron incapaces de responder a la consideración moral (y jurídica) de que es impermisible dañar a una persona inocente por una razón comparativamente trivial como proseguir con un experimento. ${ }^{66} \mathrm{Al}$ mismo tiempo, sin embargo, di-

64 Es importante aclarar que no es parte de mi postura que los factores situacionales estudiados por el situacionismo necesariamente produzcan manifestaciones de irracionalidad. Antes bien, concuerdo con Vargas (Vargas, Manuel, "Situationism and Moral Responsibility: Free Will in Fragments", en Clark, Andy et al. (eds.) Decomposing the Will, Oxford, Oxford University Press, pp. 325-350) en que dichos factores pueden, en ocasiones, potenciar las capacidades de las personas para detectar y responder a las consideraciones normativas relevantes.

65 Milgram, Stanley, Obedience to Authority, Nueva York, Harper and Row, 1974.

66 Sin embargo, hay evidencia de que la mayoría de los sujetos que obedecieron las órdenes del experimentador sí reconocieron que la consideración moral de no dañar inocentes era relevante en su situación. La evidencia consiste en el extremo 
chos sujetos sí respondieron a la consideración moral — de menor peso pero de cualquier modo no desdeñable- acerca de la importancia de completar la parte que le corresponde a cada quien en un curso de acción previamente acordado. Ello sugiere que las presiones situacionales presentes en los experimentos de Milgram, si bien afectaron la capacidad de la mayoría de los sujetos para responder a la consideración moral de mayor peso, no los incapacitaron globalmente para detectar y responder a consideraciones normativas relevantes.$^{67}$ En otras palabras, dichas presiones afectaron la capacidad de la mayoría de los sujetos para responder a cierta clase de consideraciones en cierto tipo de circunstancias. La evidencia disponible hace razonable suponer que los sujetos obedientes carecían de rasgos de personalidad inusuales que los llevaran a dañar a otros por motivos comparativamente triviales de manera rutinaria, lo cual refuerza la tesis de que la capacidad de las personas para responder adecuadamente incluso a una consideración moral tan básica como la de no producir daño gratuitamente se ve constreñida por factores situacionales. ${ }^{68}$ De ello se sigue, además, que inferencias del tipo

estado de ansiedad que exhibieron dichos sujetos, el cual se explica por el conflicto que ellos mismos percibieron entre aquella consideración y la obediencia supuestamente debida al experimentador. Véase Milgram, Stanley, "Behavioral Study of Obedience", cit., p. 375.

67 Como explico en la nota previa, a pesar de que los sujetos obedientes no respondieron a la consideración de no dañar a inocentes, ellos dieron muestras de haber detectado la relevancia de dicha consideración. Ello refuerza la interpretación de que el escenario creado por Milgram no afectó globalmente las capacidades morales de los sujetos.

68 Otra evidencia importante en apoyo de esta afirmación proviene de las variantes del paradigma original de Milgram, las cuales demuestran que pequeños cambios en la estructura de la situación modifican sustancialmente la tasa de obediencia. Por ejemplo, cuando los sujetos podían elegir la magnitud de los electrochoques, sólo 3 por ciento aplicó el máximo nivel posible de castigo contra 65 por ciento en el experimento original en el que la severidad del castigo estaba fijada de antemano por el experimentador (Milgram, Stanley, Obedience to Authority, cit., p. 61). Cuando el experimentador no se hallaba físicamente presente junto al sujeto sino que transmitía sus instrucciones por teléfono, la tasa de obediencia cayó a 21 por ciento (Ibidem, p. 60). Por el contrario, cuando la tarea del sujeto no consistía en aplicar electrochoques sino en realizar las preguntas al supuesto alumno, 93 por ciento de los sujetos colaboró con el experimentador hasta el final (Ibidem, p. 119). 
"dado que Manuel es una persona de bien jamás se contaría entre los obedientes en un escenario tipo Milgram" suelen ser ilegítimas: ${ }^{69} \mathrm{el}$ hecho de que Manuel se abstenga regularmente de dañar a inocentes por razones triviales no implica que sea razonable esperar que lo hará en cualquier situación, incluyendo situaciones tipo Milgram en las que no existe coerción o algún otro factor que sea reconocido por la moral o el derecho como un atenuante de responsabilidad.

La evidencia acerca del efecto del espectador sustenta también las dos implicaciones derivadas del situacionismo mencionadas antes, a saber, que 1) las capacidades racionales relevantes para la responsabilidad están indexadas a consideraciones y circunstancias específicas; y 2) las inferencias transituacionales acerca de lo que es razonable esperar de dichas capacidades suelen ser ilegítimas. En apoyo de la primera implicación basta notar que la difuminación de la responsabilidad y la ignorancia plural que, al conjuntarse, producen el efecto del espectador afectan únicamente la capacidad de los sujetos para responder a cierta clase de consideración (la necesidad de socorrer a otros) en cierta clase de circunstancias (cuando hay dos o más personas presentes y la situación es ambigua). No hay razones para pensar que los sujetos que participaron en estos experimentos eran inusualmente insensibles a la consideración de prestar ayuda a otros en cualquier contexto, ni tampoco para pensar que las presiones situacionales estudiadas en estos experimentos afectaron globalmente las capacidades de los sujetos para reconocer y responder a todo tipo de consideraciones morales. De lo anterior podemos concluir —en apoyo de la segunda implicación- que es ilegítimo inferir que una persona que suele ayudar a otros lo hará también en situaciones de este tipo y, a la inversa, es ilegítimo inferir que una persona que no respondió adecuadamente en ellas posee rasgos de carácter inusuales que lo vuelven regularmente insensible a las necesidades de otros en la mayoría de los contextos.

Sostengo, pues, que la evidencia situacionista demuestra la falsedad del supuesto de que las capacidades racionales relevantes para

69 Lo mismo sucede con inferencias como "dado que Juan aplicó el máximo castigo en el experimento, seguramente suele mostrar falta de consideración hacia los intereses de los demás en su vida diaria". 
las atribuciones de responsabilidad son capacidades generales. ${ }^{70}$ ¿Qué consecuencias tiene esto para la concepción tradicional de la responsabilidad moral y jurídica? A continuación exploro una de las consecuencias importantes.

\section{Situacionismo, excusas y exenciones}

Afirmé antes (subsección 2.2) que el supuesto de capacidades racionales generales está detrás de la asunción, usual en el derecho y la moral, de que las personas siempre están en posición de reconocer lo que la ley, y en particular el derecho penal, les exige (o prohíbe) y actuar en consecuencia y, por tanto, que son jurídica y moralmente responsable por acciones tipificadas como criminales a menos que esgriman exitosamente alguna de las excusas o exenciones legal y moralmente reconocidas. ${ }^{71}$ Se asume, pues, que los límites de las capacidades racionales, y por tanto los límites de aquello que es razonable esperar moral y jurídicamente de las personas, están demarcados adecuadamente por las excusas y exenciones tradicionales. Sostengo, sin embargo, que la falsedad del supuesto de capacidades racionales generales pone en entredicho la validez de esta asunción: si, como he argumentado, factores situacionales aparentemente nimios afectan sustantivamente las capacidades para detectar y res-

70 Vale la pena notar que existen muchos otros programas de investigación aparte del situacionismo que confluyen en la concepción "acotada" (bounded) de las capacidades racionales, es decir, que conciben a éstas como extremadamente sensibles a contextos específicos de acción y razonamiento. Entre ellos se encuentran la teoría de los "pequeños empujones" (nudges) en economía conductual (véase Sunstein, Cass, Human Agency and Behavioral Economics, Palgrave Macmillan, 2017); la literatura acerca de cómo la pericia (expertise) en un dominio no necesariamente se traslada a otro dominio aparentemente similar (véase Ceci, Stephen, On Intelligence... More or Less: A Biological Treatise on Intellectual Development, Cambridge, MA, Harvard University Press, 2009); y el famoso programa de investigación en psicología cognitiva acerca de los sesgos y heurísticos que empleamos los seres humanos para afrontar una multitud de tareas (véase Gilovich, Thomas, Griffin, Dale y Kahneman, Daniel (eds.), Heuristics and Biases, Cambridge, Cambridge University Press, 2002).

71 Véase Morse, Stephen, "Responsibility and Mental Capacity”, cit. 
CIENCIAS DE LA MENTE Y RESPONSABILIDAD JURÍDICA...

ponder a consideraciones normativas, es posible que algunos de los estándares en la moral y en el derecho acerca de lo que es razonable esperar de las personas sean infundados. En otras palabras, es posible que las categorías de exenciones y excusas deban ensancharse para incluir al menos algunos de los factores situacionales descritos arriba.

La respuesta habitual a esta sugerencia es que la mera presencia de factores causalmente relevantes en la producción de una acción no basta para concluir que el agente no es responsable por ella. ${ }^{72}$ De acuerdo con esta posición, sólo cuando alguno de esos factores socava la capacidad del agente para actuar racionalmente (como ocurre, por ejemplo, con las compulsiones irresistibles) o cuando vuelve demasiado costoso para éste hacer lo moralmente correcto (por ejemplo en el caso de las amenazas extremas) podemos admitirlo como una exención o una excusa. ${ }^{73}$ Así pues, dado que los factores causales identificados por el situacionismo no hacen ni lo uno ni lo otro, puede descartarse de inmediato la sugerencia de que al menos algunos de ellos deben ser considerados como eximentes de responsabilidad. ${ }^{74}$

El problema con esta respuesta es que incurre en una petición de principio, pues parte del supuesto de que los factores causales que socavan las capacidades para actuar correctamente son únicamente aquellos que ya se cuentan entre las excusas y exenciones usuales. Sin embargo, precisamente lo que el argumento esbozado arriba (4.3.1) pretende mostrar es que factores situacionales que no son reconocidos como excusas o exenciones afectan sustantivamente

72 Schoeman, Ferdinand, "Statistical Norms and Moral Attributions", en Schoeman, Ferdinand (ed.), Responsibility, Character and the Emotions, pp. 287-315, Cambridge, Cambridge University Press, 1987; McKenna Michael y Warmke, Brandon, "Does Situationism Threaten Free Will and Moral Responsibility?", Journal of Moral Philosophy, vol. 14, núm. 6, 2017, pp. 1-36.

73 Schoeman, Ferdinand, op. cit., p. 302; Morse, Stephen, "New Neuroscience, Old Problems", en Garland, Brent (ed.), Neuroscience and the Law: Brain, Mind, and the Scales of Justice, Nueva York, Dana Press, 2004, p. 180.

74 Schoeman, Ferdinand, op. cit., pp. 306, 308; Brink, David, "Situationism, Responsibility, and Fair Opportunity”, Social Philosophy \& Policy, vol. 30, núm. 1-2, 2013, pp. 139-40. 
dichas capacidades. La respuesta a este argumento pierde de vista que al menos algunos de los factores identificados en los experimentos situacionistas tienen algo importante en común con las excusas y exenciones moral y jurídicamente reconocidas, a saber, que tanto aquéllos como éstas afectan aquello que es razonable esperar de las personas con respecto al cumplimiento de las obligaciones morales y jurídicas dado que interfieren con sus capacidades para detectar y/o responder a consideraciones normativas relevantes. ${ }^{75}$ Es cierto que dichos factores situacionales operan más sutilmente que otro tipo de causas - como la demencia o la compulsión- que se admiten como exenciones, y también es cierto que aquéllos no imponen costos excesivos al cumplimiento de ciertas obligaciones del modo en que la coerción - una de las excusas por excelencia- en ocasiones lo hace; pero, aun así, al disminuir significativamente la oportunidad de los agentes para adecuar su conducta a las exigencias morales y jurídicas pertinentes, al menos algunos de los factores identificados por el situacionismo parece que deberían aceptarse como condiciones que mitigan, e incluso eximen, de responsabilidad moral y jurídica.

Nótese que matizo mi conclusión: no he dicho que al menos algunos de aquellos factores situacionales deben aceptarse como excusas o exenciones en la moral y en el derecho; he dicho sólo que parece que deberían aceptarse. Defender la conclusión en su forma más fuerte requeriría más trabajo del que puedo realizar aquí. ${ }^{76}$ Por el momento, me conformo con haber mostrado que la suposición de que las excusas y exenciones tradicionales definen adecuadamente los límites de las capacidades racionales y por tanto los límites de la responsabilidad moral y jurídica es seriamente puesta en entredicho por la evidencia situacionista. En la siguiente sección exploro la relevancia de esta conclusión para evaluar un tipo particular de disposiciones jurídicas: las leyes del buen samaritano.

75 Ahondo en este punto en la subsección 5.2.

76 Realizo el trabajo requerido para sustentar la tesis más fuerte en mi artículo Rudy-Hiller, Fernando, "Reasonable expectations, moral responsibility, and empirical data", Philosophical Studies, 2019, disponible en: https://link.springer.com/article/10.1007/s11098-019-01354-5. 
CIENCIAS DE LA MENTE Y RESPONSABILIDAD JURÍDICA...

\section{EL SITUACIONISMO Y LAS LEYES DEL BUEN SAMARITANO}

\section{Las leyes del buen samaritano}

Las leyes del buen samaritano son disposiciones jurídicas de carácter penal que exigen a quien presencie una emergencia prestar ayuda a la víctima siempre y cuando ello no conlleve un riesgo de daño físico severo. ${ }^{77}$ Las penas contempladas en caso de no prestar ayuda van desde una multa hasta varios años de prisión. ${ }^{78}$ Dichas disposiciones son mucho más comunes en el derecho continental que en el derecho anglosajón: ${ }^{79}$ mientras que en Europa continental y América Latina la mayoría de los países han adoptado algún tipo de ley del buen samaritano, el grueso de los países que se rigen por el common law no contempla este tipo de disposiciones. ${ }^{80}$

77 Véase Pardun, John, “Good Samaritan Laws: A Global Perspective”, Loyola of Los Angeles International and Comparative Law Review, vol. 20, 1998, pp. 591-613. En jurisdicciones donde impera el derecho anglosajón, el término "ley del buen samaritano" se usa normalmente para designar disposiciones jurídicas que protegen de responsabilidad civil a aquellas personas que prestan ayuda a otras de manera voluntaria cuando sus esfuerzos resultan contraproducentes; dichas disposiciones no exigen prestar ayuda, ni siquiera cuando hacerlo no conllevaría ningún riesgo importante. Algunos autores se refieren a las disposiciones que sí exigen prestar ayuda y que sancionan a quienes no lo hacen como "leyes del mal samaritano" (Feinberg, Joel, "The Moral and Legal Responsibility of the Bad Samaritan", en Feinberg, Joel, Freedom and Fulfillment, Princeton, NJ, Princeton University Press, 1992, pp. 175-196) o, más frecuentemente, como "leyes del deber de rescate" (Swan, Sarah, "Bystander Interventions”, Wisconsin Law Review, vol. 6, 2015, pp. 975-1047).

78 El artículo 323c del código penal alemán contempla una pena de hasta un año de prisión para quien no socorra a la víctima en situaciones de este tipo, mientras que el artículo 63 del código penal francés contempla una pena de hasta cinco años de cárcel. La más draconiana de estas disposiciones se halla en la sección 155 del código penal del Territorio del Norte de Australia, pues contempla una pena de hasta siete años de cárcel.

79 Schiff, Damien, "Samaritans: Good, Bad and Ugly: A Comparative Law Analysis”, Roger Williams University Law Review, vol. 11, núm. 1, 2005, p. 79.

80 Las excepciones son los estados de Vermont, Minnesota, Wisconsin y Rhode Island en Estados Unidos y el Territorio del Norte en Australia. 
El deber de rescate impuesto por las leyes del buen samaritano es bastante mínimo. Usualmente, contactar a las autoridades o al personal médico competente basta para cumplir con él. ${ }^{81}$ Lo que estas disposiciones sancionan es la omisión de prestar algún tipo de ayuda cuando la gravedad de la situación es patente, el potencial rescatista cuenta con las habilidades mínimas para ayudar o buscar ayuda de otros y no existe además peligro alguno para él mismo. Sin embargo, y a pesar de estos modestos requisitos, muchos teóricos anglosajones cuestionan la validez del supuesto deber jurídico de rescate. Ellos objetan, por un lado, que prestar ayuda en estos casos equivale a un acto de beneficencia y que es ilegítimo emplear el derecho para forzar a los ciudadanos a concederse beneficios mutuos; por otro, objetan que es imposible demarcar de manera no arbitraria aquellos casos en los que el supuesto deber de prestar ayuda entra en juego de aquellos casos en los que no. ${ }^{82}$ En lo que sigue, asumiré sin mayor discusión que estas objeciones pueden solventarse y asumiré por tanto que las leyes del buen samaritano son conceptualmente aceptables. Mi pregunta será, más bien, si estas leyes son empíricamente aceptables a la luz de la evidencia situacionista, en particular la evidencia acerca del efecto del espectador. Para enfocar la discusión, a continuación describiré un caso de aplicación de la ley del buen samaritano ocurrido hace unos años en Alemania.

\section{Un caso reciente}

El 3 de octubre de 2016, en la ciudad de Essen al noroeste de Alemania, un hombre de 83 años entró en un kiosco de cajeros automáticos y resbaló antes de llegar a uno de ellos; la fuerte caída le hizo perder la conciencia. Al poco tiempo, cuatro clientes arribaron en sucesión al lugar para realizar alguna transacción. A pesar de que el hombre se hallaba tendido a plena vista en mitad del kiosco, nin-

81 Schiff, Damien, op. cit., p. 103.

82 Véase Feinberg, Joel, op. cit., para una lúcida discusión y crítica de los principales argumentos que objetan las leyes del buen samaritano en términos conceptuales. 
CIENCIAS DE LA MENTE Y RESPONSABILIDAD JURÍDICA...

guno de los clientes se detuvo para auxiliarlo o siquiera para constatar que se encontrara bien. De acuerdo con el reporte policial basado en las grabaciones de las cámaras de seguridad, los clientes pasaron muy cerca de la víctima e incluso alguno de ellos pasó sobre ella (sin pisarla) para realizar sus transacciones. No fue sino hasta veinte minutos después que un quinto cliente finalmente llamó a una ambulancia; la víctima murió en el hospital una semana después. Once meses más tarde, en septiembre de 2017, tres de los cuatro clientes ${ }^{83}$ fueron sancionados con multas de entre 2,300 y 3,500 euros por haber infringido la sección 323c del Código Penal alemán que versa sobre "omisiones de efectuar un rescate sencillo" y que impone penas de hasta un año de prisión. En su defensa, los acusados sostuvieron que, dado que los vagabundos suelen dormir en los kioscos de cajeros automáticos de la ciudad, ellos asumieron que la víctima simplemente buscaba refugio. "No se dieron cuenta de que se trataba de una emergencia; juzgaron mal la situación”, dijo el abogado de uno de ellos. Sin embargo, el juez rechazó esta explicación debido, primero, a que la apariencia del hombre no correspondía con la de un vagabundo y, segundo, a que incluso si fuera un vagabundo los acusados tenían la obligación de socorrerlo. ${ }^{84}$ El caso provocó un gran revuelo en Alemania, donde se discutió si constituía "el símbolo de una sociedad indiferente donde nadie se preocupa por su vecino". 85

83 El cuarto cliente no fue sometido a juicio por hallarse enfermo.

84 Esta última afirmación del juez parece basarse en la idea de que una persona razonable (o razonablemente preocupada por los otros) habría verificado si el supuesto vagabundo necesitaba ayuda o no. Si esto es lo que el juez tenía en mente, la afirmación es absurda: si, como efectivamente ocurre en Essen, los vagabundos suelen refugiarse en los kioscos de cajeros automáticos porque están climatizados y el acceso es libre (hechos que ni el juez ni el fiscal negaron), entonces es absurdo sostener que una persona razonable revisaría uno por uno a los vagabundos que encuentre en dichos lugares para cerciorarse de si están gravemente enfermos o sólo duermen. Tal persona daría muestras de santidad o compulsión pero no de razonabilidad, tal como ésta se entiende en el estándar de la persona razonable empleado en el derecho.

85 Disponible en: http://www.sueddeutsche.de/panorama/prozess-in-essen-auf -dem-herzen-blind-1.3671985 y http://www.sueddeutsche.de/panorama/sterbender -in-bankfiliale-in-essen-ich-habe-noch-nichts-vergleichbares-erlebt-1.3670785. 


\section{El deber de prestar ayuda en emergencias y el efecto del espectador}

A la luz de la evidencia acerca del efecto del espectador descrita arriba, ¿es razonable concluir, como lo hizo el juez de distrito de Essen, que las personas que no socorrieron a la víctima en este caso eran moral y jurídicamente culpables por su omisión? La respuesta afirmativa se basa en la idea de que un adulto normal siempre está en posición de reconocer una situación de emergencia y de actuar apropiadamente ante ella; se basa, por tanto, en el supuesto de capacidades racionales generales. Sin embargo, si, como he argumentado arriba (4.3.1), tenemos buenas razones para rechazar este supuesto, entonces resulta menos claro que los clientes (aparentemente) indiferentes ante el predicamento de la víctima fueran moral y jurídicamente responsables por la omisión de prestar ayuda. Esta duda cobra mayor fuerza si notamos que en este caso se conjuntaron los tres principales factores que, de acuerdo con la evidencia descrita antes (4.2.1), inhiben la propensión de las personas a intervenir ante una emergencia: difuminación de la responsabilidad a causa de la presencia de otros, ignorancia plural debida a la ambigüedad de la situación y aversión a socorrer a una víctima estigmatizada moralmente.

Ahora bien, es evidente que los tres factores recién mencionados no se hallan en pie de igualdad por lo que toca a su impacto sobre las atribuciones de responsabilidad moral y jurídica. Si, por ejemplo, alguno de los acusados no ayudó a la víctima simplemente porque le dio asco acercarse a quien creía que era un vagabundo - a pesar de haber reconocido que requería asistencia médica urgente- o porque pensó que no merecía ayuda al considerarlo parcialmente responsable por su predicamento, difícilmente (y con razón) aceptaríamos esto como una excusa. Lo mismo ocurriría si uno o varios de los acusados se hubieran percatado de la potencial gravedad de la situación pero no intervinieron debido a que no consideraron que era su deber hacerlo. Por otro lado, el proceso psicológico de ignorancia plural resulta más pertinente para evaluar la responsabilidad de quienes no prestaron ayuda puesto que es directamente relevante 
CIENCIAS DE LA MENTE Y RESPONSABILIDAD JURÍDICA...

para responder a la pregunta crucial: dada la situación tal como ha quedado descrita, ¿era razonable esperar que las personas percibieran la situación como una emergencia en primer lugar? ${ }^{86}$

Considérese la siguiente explicación situacionista del caso. Los clientes entran en sucesión al kiosco de cajeros automáticos y ven que al menos otra persona está llevando a cabo sus transacciones con normalidad a pesar del hombre tirado en la entrada (esto, obviamente, con excepción del primero de los cuatros clientes). Ninguno de los clientes piensa que le incumbe directamente a él o ella cerciorarse de la condición del hombre y, a su vez, la inacción de los otros refuerza la interpretación de la situación como una no emergencia, especialmente porque es del dominio público que vagabundos utilizan el kiosco para refugiarse y dormir en él. Como señala Darley, uno de los descubridores del efecto del espectador:

Las emergencias no traen consigo un anuncio que dice "Soy una emergencia". Para interpretar un evento como una emergencia, uno se fija en las reacciones de los otros y desentraña el significado detrás de dichas reacciones. ${ }^{87}$

En este caso, el significado obvio detrás de la reacción de los otros clientes - continuar tranquilamente con sus transacciones a pesar del hombre tirado en el vestíbulo - era, precisamente, que no había emergencia alguna. Si, como muestra la evidencia experimental, resulta usual interpretar una situación ambigua como una no emergencia cuando los individuos la atestiguan en presencia de otros quienes se muestran despreocupados, ello sugiere que no era razo-

86 Ésta es la pregunta crucial porque las leyes del buen samaritano incorporan el requisito de que el potencial rescatista sepa o esté consciente de que la situación es una emergencia (Schiff, Damien op. cit., p. 104; Pardun, John, op. cit., p. 610). De igual modo, usualmente se admite que para ser moralmente responsable por una acción u omisión es necesario que la persona esté al tanto de la naturaleza de ésta (Rudy-Hiller, Fernando, “The Epistemic Condition...”, cit.). Si los acusados no sabían que la víctima requería asistencia médica urgente a fortiori no estaban al tanto de la naturaleza de su omisión, pues desconocían que su acción de continuar con sus transacciones financieras implicaba la omisión de prestar asistencia urgente.

87 Citado en Evans, Richard, The Making of Social Psychology, Nueva York, Gardner Press, 1980, p. 216. 
nable esperar que los acusados se dieran cuenta de la gravedad de la situación y actuaran en consecuencia. ${ }^{88}$

Hay tres maneras alternativas de explicar por qué la ausencia de esta expectativa razonable mitiga, o incluso elimina, la responsabilidad de los acusados. ${ }^{89}$ Una primera explicación es que los factores situacionales degradaron (localmente) la capacidad de los agentes para percatarse de la gravedad de la situación y formular un plan de acción apropiado, y lo hicieron más allá del límite por debajo del cual cesan de contar como agentes responsables en dichas circunstancias y con respecto a las consideraciones pertinentes. Si éste es el caso, entonces los factores situacionales referidos exentarían de responsabilidad. ${ }^{90}$ Una segunda explicación es que estos factores situacionales, si bien no son lo suficientemente potentes como para degradar la capacidad cognitiva de los sujetos por debajo del umbral crítico, sí vuelven muy difícil para éstos percatarse de las consideraciones relevantes (que se trata de una emergencia, que es imperativo pedir ayuda). En este caso, dichos factores excusarían, quizá parcialmente, de responsabilidad, al producir en los sujetos un estado de ignorancia no culpable respecto de las consideraciones relevantes. Finalmente, una tercera explicación es que los factores situacionales involucrados excusan porque muestran que los acusados

88 Uno podría objetar esta conclusión recordando que, después de todo, el quinto cliente sí reconoció que se trataba de una emergencia y actuó apropiadamente (llamó a una ambulancia). El problema es que el mero hecho de que una persona perciba correctamente la situación y reaccione adecuadamente no muestra que es razonable esperar que la mayoría lo hará. Esto es relevante porque el grueso de las obligaciones morales y jurídicas no exige comportamiento extraordinario o fuera de lo común y lo que la evidencia situacionista muestra es, precisamente, que reaccionar adecuadamente ante una emergencia cuando ésta es ambigua y se está en presencia de otros es más bien la excepción que la norma. Además (y éste es el punto crucial), dicha evidencia se complementa con una explicación de por qué ocurre este fenómeno, la cual, como he argumentado, resulta directamente relevante para evaluar las atribuciones de responsabilidad, puesto que muestra cómo los procesos psicológicos involucrados socavan localmente la capacidad cognitiva requerida para actuar correctamente 0 , al menos, la oportunidad adecuada para ejercitarla.

89 Para una taxonomía similar de las condiciones de exculpación, véase Vargas, Manuel, Building Better Beings, cit., pp. 234-40.

90 Véase la nota 10 para la distinción entre exenciones y excusas. 
CIENCIAS DE LA MENTE Y RESPONSABILIDAD JURÍDICA...

no actuaron con mala voluntad al no prestar ayuda, esto es, su inacción se explicaría por factores situacionales y no por disposiciones individuales moral y jurídicamente censurables. Para los propósitos de este trabajo, no es necesario decidir cuál de estas tres explicaciones es la correcta; basta con señalar que cualquiera de ellas ofrece buenas razones para dudar de la culpabilidad moral y jurídica de los acusados.

Si ello es así, la inacción de estas personas no necesariamente reflejó, como lo creyó el juez del caso, indiferencia ante el sufrimiento ajeno, sino muy posiblemente tan solo su percepción (razonable, dada la naturaleza de la situación) de que su ayuda no era requerida o quizá su incapacidad local para percatarse de las consideraciones relevantes. De ser éste el caso, entonces la evidencia empírica refuta las dos consideraciones que justificaron la sanción impuesta por el juez: por un lado, la supuesta expectativa razonable de que cualquier persona normal habría reconocido la situación como una emergencia y, por otro, la interpretación de su omisión de prestar ayuda como reflejo de un rasgo de carácter moralmente reprobable. En la medida en que las violaciones a las leyes del buen samaritano ocurran en contextos similares a éste, la evidencia empírica socava de manera general la justedad de las sanciones aplicadas con base en ellas. ${ }^{91}$

\section{CONCLUSIÓN}

En este trabajo he defendido dos tesis principales. En primer lugar, he argumentado que el reto global de las ciencias de la mente contra

91 Sin embargo, dichas sanciones podrían justificarse todavía apelando a consideraciones puramente consecuencialistas, como por ejemplo que la existencia del deber jurídico de prestar ayuda junto con la amplia difusión de las sanciones impuestas a aquellos que no cumplen con él contribuyen a eliminar tanto la difuminación de la responsabilidad como la ignorancia plural (Swan, Sarah, op. cit., p. 986). Si esto último efectivamente ocurriera en cierta comunidad, entonces las sanciones subsecuentes a quienes no presten ayuda podrían estar justificadas también en términos retributivos, esto es, relacionados con el merecimiento de castigo de quien, siendo capaz de cumplir con la obligación en cuestión, no lo hizo. 
la responsabilidad jurídica, según el cual aquéllas muestran que la psicología de sentido común presupuesta en el derecho es simplemente falsa y por tanto la responsabilidad jurídica es una quimera, no es exitoso. Sostuve, en particular, que la evidencia actualmente disponible no muestra que el supuesto de causación mental es falso $y$, por tanto, no muestra que las personas somos incapaces de guiar nuestra conducta con base en intenciones formadas a la luz de nuestras razones. En pocas palabras, la evidencia disponible no muestra que no somos agentes. Pero, en segundo lugar, he argumentado que sí existe evidencia convincente de que no somos exactamente la clase de agentes que creemos ser. En particular, he sostenido que el supuesto de capacidades racionales generales incorporado en el derecho y, particularmente, en el derecho penal, es falso: las capacidades moral y jurídicamente relevantes para las atribuciones de responsabilidad - las capacidades para detectar y responder a consideraciones normativas- no son estables a través de diferentes circunstancias. Más bien, dichas capacidades están indexadas a contextos específicos de acción, lo cual significa que las personas somos variablemente capaces de detectar y responder a ciertas consideraciones en ciertos contextos. Ello implica que, contra lo que asumen las teorías tradicionales de la responsabilidad moral y jurídica, los límites de las capacidades relevantes para las atribuciones de responsabilidad no coinciden con las excusas y exenciones usualmente reconocidas. Por último, ilustré la relevancia de esta conclusión para el derecho discutiendo las leyes del buen samaritano. Argumenté que, en muchos casos, la aplicación de sanciones con base en ellas corre el riesgo de ser injusta precisamente porque se basa en el supuesto de capacidades racionales generales que el situacionismo contribuye a desmentir.

No obstante, podría objetarse que este ejemplo es más bien periférico dentro del derecho penal y por tanto que su relevancia es limitada para la comprensión adecuada de éste. En respuesta, si bien concedo que las leyes del buen samaritano no necesariamente ocupan un lugar prominente en el derecho penal, sostengo que el ejemplo sí cumple a cabalidad con el propósito central del artículo, a saber, mostrar cómo la evidencia empírica es relevante para el derecho. Desde luego, quedan por explorar las repercusiones que pu- 
diera tener el rechazo del supuesto de capacidades racionales generales en casos de mayor envergadura, como por ejemplo crímenes cometidos siguiendo órdenes de personas en posiciones de autoridad. ${ }^{92}$ El punto esencial que he buscado defender, sin embargo, es que, antes que una amenaza inminente para la integridad del derecho, las ciencias de la mente y del comportamiento tienen el potencial de convertirse en aliadas de éste para establecer disposiciones - e imponer sanciones - más acordes con las peculiaridades de la agencia humana. ${ }^{93}$

\section{REFERENCIAS}

BAYnE, Tim, "Phenomenology and the Feeling of Doing: Wegner on the Conscious Will”, en Pockett, Susan, Banks, William y Gallagher, Shaun (eds.), Does Consciousness Cause Behavior?, Cambridge, MIT Press, 2006.

BRINK, David, "Situationism, Responsibility, and Fair Opportunity", Social Philosophy \& Policy, vol. 30, núm. 1-2, 2013.

Broome, John, Rationality through Reasoning, Malden, Wiley-Blackwell, 2013.

92 El libro de Philip Zimbardo (The Lucifer Effect: Understanding How Good People Turn Evil, Nueva York, Random House, 2007) es muy pertinente a este respecto, puesto que en él se exploran precisamente las influencias situacionales sistémicas que posibilitan que gente ordinaria cometa actos de maldad extraordinaria, por ejemplo en estructuras jerárquicas de mando. Además, y como bien lo indica un dictaminador anónimo, los hallazgos de este libro se compadecen bien con la legislación penal internacional (por ejemplo la que rige en la Corte Penal Internacional), según la cual la responsabilidad jurídica de los altos mandos es mayor que la de quienes, siguiendo órdenes de éstos, en ocasiones sucumben a presiones situacionales como las descritas en los experimentos de Milgram. Ello en efecto muestra que, como lo señala el dictaminador, "no siempre las normas jurídicas manifiestan un desfase con los descubrimientos de las ciencias del comportamiento".

93 Investigación realizada gracias al Programa UNAM-PAPIIT IA400318 "Hacia una teoría social de la responsabilidad moral". Agradezco también a los participantes del Seminario de Filosofía Práctica del IIF-UNAM por sus comentarios y a dos dictaminadores anónimos por sus sugerencias. 
CAShmore, Anthony, "The Lucretian Swerve: The Biological Basis of Human Behavior and the Criminal Justice System", Proceedings of the National Academy of Sciences of the United States of America, vol. 107, núm. 10, 2010.

CECI, Stephen, On Intelligence... More or Less: A Biological Treatise on Intellectual Development, Cambridge, Harvard University Press, 2009.

DAHAN-KaTz, Leora, "The Implications of Heuristics and Biases Research on Moral and Legal Responsibility", en Vincent, Nicole (ed.), Neuroscience and Legal Responsibility, pp. 135-156, Oxford, Oxford University Press, 2013.

DARLEY, John y Batson, Daniel, "From Jerusalem to Jericho: A Study of Situational and Dispositional Variables in Helping Behavior", Journal of Personality and Social Psychology, vol. 27, núm. 1, 1973.

Davidson, Donald, “Actions, Reasons, and Causes”, en Davidson, Donald, Essays on Actions and Events, Oxford, Oxford University Press, 1980.

DAviES, Paul, "Skepticism Concerning Human Agency: Sciences of the Self Versus 'Voluntariness' in the Law", en Vincent, Nicole (ed.), Neuroscience and Legal Responsibility, Oxford, Oxford University Press, 2013.

DAwkins, Richard, "Let's All Stop Beating Basil's Car", Edge: The World Question Center, 2006, disponible en: https://www. edge.org/q2006/q06_9.html.

Duff, Anthony, Punishment, Communication and Community, Nueva York, Oxford University Press, 2001.

Duff, Anthony, "What Kind of Responsibility Must Criminal Law Presuppose?", en Swinburne, Richard (ed.), Free Will and Modern Science, Oxford, Oxford University Press, 2011.

Duff, Anthony, Farmer, Lindsay, Marshall, Sandra y Tadros, Victor, The Trial on Trial: Towards a Normative Theory of the Criminal Trial, vol. 3, Oxford, Hart, 2007. 
Evans, Richard, The Making of Social Psychology, Nueva York, Gardner Press, 1980.

FEINBERG, Joel, "The Moral and Legal Responsibility of the Bad Samaritan"

FeInberG, Joel, Freedom and Fulfillment, Princeton, Princeton University Press, 1992.

FISCHER, Peter et al., "The Bystander-Effect: A Meta-Analytic Review of Bystander Intervention in Dangerous and Non-Dangerous Emergencies", Psychological Bulletin, vol. 137, núm. 4, 2011.

Fischer, John y RavizzA, Mark, Responsibility and Control: A Theory of Moral Responsibility, Cambridge, Cambridge University Press, 1998.

GazzAnigA, Michael, "The Law and Neuroscience", Neuron, vol. 60, 2008.

Gilovich, Thomas et al. (eds.), Heuristics and Biases, Cambridge, Cambridge University Press, 2002.

Glannon, Walter, "Neurobiology, Neuroimaging, and Free Will”, Midwest Studies in Philosophy, vol. 29, 2005.

Greene, Joshua y Cohen, Jonathan, "For the Law, Neuroscience Changes Nothing and Everything", Philosophical Transactions of the Royal Society of London, vol. 359, núm. 1451, 2004.

HART, Herbert, "Postscript: Responsibility and Retribution", en HART, Herbert, Punishment and Responsibility, Oxford, Clarendon Press, 1968.

IsEN, Alice y LEvin, Paula, "Effect of Feeling Good on Helping", Journal of Personality and Social Psychology, vol. 21, núm. 3, 1972.

LATANÉ, Bibb y DARLEY, John, The Unresponsive Bystander: Why Doesn't He Help?, Nueva York, Appleton-Century Crofts, 1970.

LATANÉ, Bibb y Rodin, Judith, "A Lady in Distress: Inhibiting Effects of Friends and Strangers on Bystander Intervention", Journal of Experimental Social Psychology, vol. 5, núm. 2, 1969.

MCKENNA Michael y WARMKE, Brandon, "Does Situationism Threaten Free Will and Moral Responsibility?", Journal of Moral Philosophy, vol. 14, núm. 6, 2017. 
Mele, Alfred, “Agents' Abilities”, Noûs, vol. 37, núm. 3, 2002.

Milgram, Stanley, "Behavioral Study of Obedience", Journal of Abnormal and Social Psychology, vol. 67, núm. 4, 1963.

Milgram, Stanley, Obedience to Authority, Nueva York, Harper and Row, 1974.

Montemayor, Carlos y Cáceres, Enrique, "Agency and Legal Responsibility: Epistemic and Moral Considerations", Problema Anuario de Filosofía y Teoría del Derecho, núm. 13, 2019.

Moore, Michael, Act and Crime: The Philosophy of Action and its Implications for Criminal Law, Oxford, Oxford University Press, 1993.

Morse, Stephen, "New Neuroscience, Old Problems", en Garland, Brent (ed.), Neuroscience and the Law: Brain, Mind, and the Scales of Justice, pp. 157-198, Nueva York, Dana Press, 2004.

Morse, Stephen, "Determinism and the Death of Folk Psychology: Two Challenges to Responsibility from Neuroscience", Minnesota Journal of Law, Science and Technology, vol. 9, núm. 1, 2008.

MoRse, Stephen, "Responsibility and Mental Capacity", en VincEnT, Nicole (ed.), Neuroscience and Legal Responsibility, Oxford, Oxford University Press, 2013.

NAgEL, Thomas, The Possibility of Altruism, Princeton, Princeton University Press, 1970.

NAHMias, Eddy, "When Consciousness Matters: A Critical Review of Daniel Wegner's The Illusion of Conscious Will", Philosophical Psychology, vol. 15, núm. 4, 2002.

NAhmias, Eddy, "Is Free Will and Illusion? Confronting Challenges from the Modern Mind Sciences", en SinnotT-Armstrong, Walter (ed.), Moral Psychology, vol. 4: Free Will and Moral Responsibility, Cambridge, MIT Press, 2014.

OLIN, Lauren y Doris, John, "Vicious Minds: Virtue Epistemology, Cognition, and Skepticism", Philosophical Studies, vol. 168, núm. 3, 2014. 
PARDuN, John, “Good Samaritan Laws: A Global Perspective”, Loyola of Los Angeles International and Comparative Law Review, 20, pp. 591-613, 1998.

Piliavin, Irving et al., "Good Samaritanism: An Underground Phenomenon?", Journal of Personality and Social Psychology, vol. 13, núm. 4, 1969.

Piliavin, Jane y Piliavin, Irving, "Effect of Blood on Reaction to a Victim", Journal of Personality and Social Psychology, vol. 23, núm. 3, 1972.

PILIAvin, Irving et al., "Costs, Diffusion, and the Stigmatized Victim", Journal of Personality and Social Psychology, vol. 32, num. 3, 1975.

Pockett, Susan et al. (eds.), Does Consciousness Cause Behavior?, Cambridge, MIT Press, 2006.

RAZ, Joseph, Practical Reason and Norms, Londres, Hutchinson, 1975.

Ross, Lee y NisbetT, Richard, The Person and the Situation: Perspectives of Social Psychology, Nueva York, McGraw-Hill, 1991.

Rudy-Hiller, Fernando, "The Epistemic Condition for Moral Responsibility", en ZaLTA, Edward N. (ed.), The Stanford Encyclopedia of Philosophy (edición verano 2018), disponible en: https://plato.stanford.edu/archives/fall2018/entries/moralresponsibility-epistemic/.

Rudy-Hiller, Fernando, "Reasonable Expectations, Moral Responsibility, and Empirical Data", Philosophical Studies, 2019. disponible en: https://link.springer.com/article/10.1007/ s11098-019- 01354-5

SABINI, John et al., "The Really Fundamental Attributional Error in Social Psychological Research", Psychological Inquiry, vol. 12, 2000.

SABInI, John y Silver, Maury, "Internal and External Causes of Behavior", International Journal of Moral and Social Studies, vol. 2, 1987. 
SAPOLSKY, Robert, "The Frontal Cortex and the Criminal Justice System", Philosophical Transactions of the Royal Society of London, 359 (1451), 2004.

Schiff, Damien, "Samaritans: Good, Bad and Ugly: A Comparative Law Analysis", Roger Williams University Law Review, 11 (1), , 2005.

Schoeman, Ferdinand, "Statistical Norms and Moral Attributions", en Schoeman, Ferdinand (ed.), Responsibility, Character and the Emotions, Cambridge, Cambridge University Press, 1987.

ShapIRo, Scott, "Law, Morality, and the Guidance of Conduct", Legal Theory, vol. 6, 2000.

Smith, Michael, The Moral Problem, Malden, Blackwell, 1994.

Sunstein, Cass, Human Agency and Behavioral Economics, Palgrave Macmillan, 2017.

SwAN, Sarah, "Bystander Interventions", Wisconsin Law Review, vol. 6, 2015.

VArgas, Manuel, Building Better Beings: A Theory of Moral Responsibility, Oxford, Oxford University Press, 2013.

VARGAS, Manuel, "Situationism and Moral Responsibility: Free Will in Fragments," en ClaRK, Andy et al. (eds.) Decomposing the Will, Oxford, Oxford University Press, 2013.

VInCENT, Nicole, "Legal Responsibility Adjudication and the Normative Authority of the Mind Sciences", Philosophical Explorations, vol. 14, núm. 3, 2011.

Wallace, Jay, Responsibility and the Moral Sentiments, Cambridge, MA, Harvard University Press, 1994.

Wegner, Daniel, The Illusion of Conscious Will, Cambridge, MIT Press, 2002.

Wegner, Daniel, "Who Is the Controller of Controlled Processes?", en HASsin, Ran et al. (eds.), The New Unconscious, Oxford, Oxford University Press, 2006.

WEGner, Daniel et al., "Clever Hands: Uncontrolled Intelligence in Facilitated Communication", Journal of Personality and Social Psychology, vol. 85, núm. 1, 2003. 
CIENCIAS DE LA MENTE Y RESPONSABILIDAD JURÍDICA...

Wegner, Daniel Et AL., "Vicarious Agency: Experiencing Control over the Movements of Others", Journal of Personality and Social Psychology, vol. 86, núm. 6, 2004.

Zimbardo, Philip, The Lucifer Effect: Understanding How Good People Turn Evil, Nueva York, Random House, 2007. 